\title{
Daily precipitation statistics in a EURO-CORDEX RCM ensemble: Added value of raw and bias-corrected high-resolution simulations
}

\author{
A. Casanueva - S. Kotlarski · S. \\ Herrera • J. Fernández • J.M. \\ Gutiérrez • F. Boberg • A. Colette • \\ O. B. Christensen • K. Goergen • D. \\ Jacob • K. Keuler • G. Nikulin • C. \\ Teichmann • R. Vautard \\ Received: date / Accepted: date
}

\author{
A. Casanueva (凶) $\cdot$ S. Herrera $\cdot$ J. Fernández \\ Grupo de Meteorología. Dpto. Matemática Aplicada y Ciencias de la Computación. Univ. \\ de Cantabria, Avda. de los Castros, s/n, 39005 Santander, Spain \\ Tel.: +34 942201723 \\ E-mail: ana.casanueva@unican.es \\ S. Kotlarski \\ Institute for Atmospheric and Climate Science, ETH Zurich, Switzerland \\ J.M. Gutiérrez \\ Grupo de Meteorología. Instituto de Física de Cantabria. CSIC-Univ. de Cantabria, Avda. \\ de los Castros, s/n, 39005 Santander, Spain \\ F. Boberg · O. B. Christensen \\ Climate and Arctic Research, Danish Meteorological Institute, Lyngbyvej 100, DK-2100 \\ Copenhagen $\varnothing$, Denmark \\ A. Colette \\ Institut National de l'Environnement industriel et des risques (INERIS), Verneuil en Ha- \\ latte, France \\ K. Goergen \\ Meteorologiocal Institute, University of Bonn, Auf dem Hügel 20, 53121 Bonn, Germany \\ (former Dpartement Environnement et Agro-Biotechnologies, Centre de Recherche Public \\ Gabriel Lippmann, 41 Rue du Brill, 4422 Belvaux, Luxembourg, since January 2015 re- \\ named to Luxembourg Science and Technology, LIST) \\ D. Jacob · C. Teichmann \\ Climate Service Center Germany (GERICS), Hamburg, Germany \\ D. Jacob \\ Max Planck Institute for Meteorology, Hamburg, Germany \\ K. Keuler \\ Chair of Environmental Meteorology, Brandenburg University of Technology (BTU), \\ Cottbus-Senftenberg, Germany \\ G. Nikulin \\ Swedish Meteorological and Hydrological Institute, Norrköping, Sweden
}


Abstract Daily precipitation statistics as simulated by the ERA-Interimdriven EURO-CORDEX regional climate model (RCM) ensemble are evaluated over two distinct regions of the European continent, namely the European Alps and Spain. The potential added value of the high-resolution 12 $\mathrm{km}$ experiments with respect to their $50 \mathrm{~km}$ resolution counterparts is investigated. The statistics considered consist of wet-day intensity and precipitation frequency as a measure of mean precipitation, and three precipitation-derived indicators (90th percentile on wet days - 90pWET - , contribution of the very wet days to total precipitation - R95pTOT - and number of consecutive dry days - CDD - ). As reference for model evaluation high resolution gridded observational data over continental Spain (Spain011/044) and the Alpine region (EURO4M-APGD) are used. The assessment and comparison of the two resolutions is accomplished not only on their original horizontal grids (approximately $12 \mathrm{~km}$ and $50 \mathrm{~km}$ ), but the high-resolution RCMs are additionally regridded onto the coarse $50 \mathrm{~km}$ grid by grid cell aggregation for the direct comparison with the low resolution simulations.

The direct application of RCMs e.g. in many impact modelling studies is hampered by model biases. Therefore bias correction (BC) techniques are needed at both resolutions to ensure a better agreement between models and observations. In this work, the added value of the high resolution (before and after the bias correction) is assessed and the suitability of these BC methods is also discussed. Three basic BC methods are applied to isolate the effect of biases in mean precipitation, wet-day intensity and wet-day frequency on the derived indicators.

Daily precipitation percentiles are strongly affected by biases in the wetday intensity, whereas the dry spells are better represented when the simulated precipitation frequency is adjusted to the observed one. This confirms that there is no single optimal way to correct for RCM biases, since correcting some distributional features typically leads to an improvement of some aspects but to a deterioration of others.

Regarding mean seasonal biases before the BC, we find only limited evidence for an added value of the higher resolution in the precipitation intensity and frequency or in the derived indicators. Thereby, evaluation results considerably depend on the RCM, season and indicator considered. High resolution simulations better reproduce the indicators' spatial patterns, especially in terms of spatial correlation. However, this improvement is not statistically significant after applying specific BC methods.

Keywords Regional Climate Models · EURO-CORDEX · added value · bias correction $\cdot$ precipitation indices

R. Vautard

LSCE-IPSL CEA /CNRS / UVSQ 91191 gif sur Yvette cedex France 


\section{$1 \quad 1$ Introduction}

2 Regional Climate Models (RCMs) are sophisticated tools that allow representing physical processes in the atmosphere that are not yet resolved by the coarse resolution of Global Climate Models (GCMs) (Giorgi, 2006; Feser et al, 2011). During the last decade, a huge effort has been made in order to adapt and apply these models to produce regional climate change scenarios in different regions worldwide. As a result, there is nowadays a number of comprehensive datasets developed in projects such as ENSEMBLES (van der Linden and Mitchell, 2009) and CORDEX (Giorgi et al, 2009), which also provide new opportunities for the intercomparison of different models, grid resolutions, boundary conditions, parameterizations (see e.g. Christensen et al, 1997; Jacob et al, 2007; Nikulin et al, 2011; García-Díez et al, 2013; Vautard et al, 2013) and model domains (Teichmann et al, 2013). For instance, the EURO-CORDEX initiative experiment design (European branch of CORDEX, http://www.euro-cordex.net/, see Jacob et al (2014) and Kotlarski et al (2014)) considers simulations at two horizontal resolutions, $0.44^{\circ}$ and $0.11^{\circ}$. The latter is computationally very costly and its benefits have just recently been questioned by Prein et al (2015).

In principle, higher resolution experiments are able to capture features related to topography or land-sea mask, which are missed by coarser ones (Pryor et al, 2012; Walther et al, 2013); however, the added value of high resolution simulations is not always evident (Chan et al, 2013). Deficiencies may be caused for example by the fact that a given model is often developed and tuned in its low-resolution version (Gibelin and Déqué, 2003), therefore the high resolution cannot systematically improve the model performance. Several studies point out the importance of the right combination of parameterizations and horizontal (e.g. Déqué et al, 2005; Prein et al, 2013) and vertical resolution (Roeckner et al, 2006), highlighting for instance the role of the convection scheme (Kendon et al, 2012). Nevertheless, a single best parameterization for a specific resolution may not exist (Fernández et al, 2007; Jerez et al, 2012; García-Díez et al, 2015), and also depends on the particular application, i.e. the final use of the RCM simulation results. Thus, this situation supports the use of ensembles sampling different parameterizations and other model settings.

Model biases typically hamper the direct application of RCM output in impact studies (see e.g. Christensen et al, 2008; Kotlarski et al, 2014). Therefore, different bias correction (BC) methods were introduced in the literature (see e.g. Panofsky and Brier, 1968; Durman et al, 2001) and they have recently become increasingly popular in their application. BC methods vary from very simple factor scaling (additive or multiplicative, Durman et al (2001); Casanueva et al (2013)), to multi-variable BC techniques for particular combinations of variables (Wilcke et al, 2013; Vrac and Friederichs, 2015) and methods pursuing the correction of more sophisticated bias features, such as temperature-dependent biases (Boberg and Christensen, 2012; Bellprat et al, 2013). BC methods applied to precipitation have traditionally relied on the 
assumption that models produce more rainy days than the reference observations (drizzle effect). There are also some BC methods dealing with dry-day frequency overestimation, such as the frequency adaptation (Themeßl et al, 2012) or the Piani et al (2010) method, modified by Argüeso et al (2013) to be used with station data.

Against the background outlined above, the aim of this study is to, first, assess the added value of high $(12 \mathrm{~km})$ versus low $(50 \mathrm{~km})$ resolution RCM simulations regarding daily precipitation statistics. For this purpose, several precipitation derived-indicators (accounting for the mean and extreme regimes) are evaluated in a EURO-CORDEX RCM ensemble. Secondly, since RCMs are prone to systematic biases, BC methods are applied and the question whether a potential added value of the raw high-resolution experiments with respect to their low-resolution counterparts also remains after bias-correction is investigated. The considered $\mathrm{BC}$ methods consist of the adjustment of the first moments of the precipitation distribution (mean precipitation, wet-day intensity and wet-day frequency), which are applied separately to isolate the effect of biases in precipitation amount and occurrence on precipitation derived indicators. Note that we do not intend to provide the optimally bias-corrected data - more sophisticated BC methods correcting the whole precipitation distribution would be needed-, but to attribute indicators' biases to deficiencies in the precipitation frequency (occurrence) and the intensity (amount). By doing this, the basic precipitation features are investigated in depth to shed light on the limitations and merits of both resolutions and to inform climate scenario end users about undesired effects which may also affect more sophisticated BC methods.

Several aspects can be analysed to assess the added value of high resolution $\mathrm{RCM}$ simulation results. In this respect, a crucial question is the spatial scale on which the evaluation and intercomparison is carried out. An evaluation on the high resolution grid would penalize the coarse simulations because even a perfect coarse simulation would miss sub-grid-scale features (Prein et al, 2015). For this reason, all comparisons are performed on the coarse resolution $(50 \mathrm{~km})$, corresponding to the skillful scale of the $12 \mathrm{~km}$ experiments (Grasso, 2000). We consider this as the 'fairest' approach since it compares features resolved by both resolutions. Nevertheless it is important to note that with this choice we do not consider all aspects of the added value, e.g. the more local information provided by the high resolution. See also Di Luca et al (2015) for a comprehensive discussion about various definitions of added value.

A further note of caution relates to the fact that our study focuses on several extreme precipitation indicators, such as the contribution of very wet days (R95pTOT), dry spell lengths (maximum number of consecutive dry days, CDD) and percentiles (90th percentile on wet days, 90pWET). These indicators are very sensitive to the definition of a wet day, which is widely discussed throughout the paper.

We consider two target areas in Europe: Continental Spain and the European Alps, where high-resolution and high-quality gridded observational data sets are available for the evaluation and where previous versions of the same 
RCMs have been examined (see e.g. Frei et al, 2003; Herrera et al, 2010). These areas cover a wide range of climatic conditions, from Mediterranean to Alpine climates, and orographic complexity.

Taking into account all the above, the specific objectives of the study are to

- examine the added value of high resolution simulations at the skillful scale $(50 \mathrm{~km})$ of the high resolution

- assess the added value of the high resolution simulations before and after bias correction

- provide some hints of possible implications of the results for more sophisticated BC methods.

This work is organized as follows. In Section 2 we present the data used. Section 3 introduces the methodology followed to evaluate the RCMs. The results are given in Section 4. Finally, the conclusion and the summary are given in Section 5 .

\section{Data}

In the present study both high-resolution observational reference and RCM output data were used. All analyses were based on the common period 19892008. The study was performed on a seasonal basis, although only winter (DJF) and summer (JJA) results are shown for the sake of conciseness.

\subsection{Observational Data}

Observations play a major role in the evaluation and bias correction procedure and, as the RCM grid cells represent areal averages, gridded observational products are usually considered for the evaluation.

Over Spain, we used the new EURO-CORDEX-compliant, gridded observational data sets (Spain011/044; Herrera et al, 2015). More than 2700 quality-controlled stations were selected to develop these gridded precipitation data sets with $0.11^{\circ}$ and $0.44^{\circ}$ horizontal resolution, regular in a rotated longitude-latitude system, covering the period from 1971 to 2010. They were interpolated following trivariate thin plate splines (TPS) and ordinary kriging (AA-3D method in Herrera et al, 2015). This interpolation process is equivalent to the one used to build the European-scale E-OBS data set (Hofstra et al, 2009), considering orography as covariable in the formulation of the TPS. In order to ensure the area-averaged representativeness, the interpolation method was applied at an auxiliary $0.01^{\circ}$ horizontal resolution grid and the final grids were obtained by averaging the results into the final resolution.

For the Alps, the Alpine Precipitation Grid Dataset (APGD, Isotta et al, 2013) was used as observational reference. This data set was developed in the 
framework of EURO4M (European Reanalysis and Observations for Monitoring) for the period 1971-2008 and is a $5 \mathrm{~km}$ resolution gridded product provided by MeteoSwiss. The interpolation procedure consists of local regression (precipitation-elevation regression on independent slopes model) and angular distance weighting. In this study, the APGD was conservatively remapped onto the rotated $0.11^{\circ}$ and $0.44^{\circ} \mathrm{RCM}$ grid, therefore the APGD011/044 versions exactly match the EURO-CORDEX grids $\left(0.11^{\circ}\right.$ and $\left.0.44^{\circ}\right)$. We re-gridded from the original $5 \mathrm{~km}$ resolution in a Lambert Azimuthal Equal Area Coordinate Reference System to $1 \mathrm{~km}$ grid in a rotated longitude-latitude system and afterwards we averaged the values inside every EURO-CORDEX grid-cell in order to guarantee the representation of areal averages.

\subsection{Regional Climate Models}

We evaluated daily precipitation from the EURO-CORDEX RCMs integrated at horizontal resolutions of $0.11^{\circ}$ and $0.44^{\circ}$ on rotated grids (Table 1 ). These simulations were driven by the ERA-Interim reanalysis (Dee et al, 2011) and covered the period 1989-2008. We refer the reader to Table 1 in Vautard et al (2013) and Table 1 in Kotlarski et al (2014) for the model details. In those tables, WRF311A and WRF311F are referred to as WRF-CRPGL and WRF-IPSL-INERIS, respectively, and these two WRF setups apply different combinations of physical parameterization schemes (details in Kotlarski et al, 2014). Most of these simulations are available via the Earth System Grid Federation (ESGF archive, http://esgf.org/) under the CORDEX initiative. Throughout this paper, the individual simulations are referred to as the name in the second column in Table 1 plus the resolution (e.g. HIRHAM011, HIRHAM044).

Table 1 EURO-CORDEX RCMs used in the present study. Codes were used to label RCMs in Figure 10. The last column indicates whether or not the respective RCM applies a smoothed surface orography.

\begin{tabular}{llll} 
Code & RCM & Institution & Orog. smoothed \\
\hline 1 & CCLM & COSMO-CLM Community & Yes \\
2 & HIRHAM & $\begin{array}{l}\text { Danish Meteorological Institute, Denmark } \\
\text { Royal Netherlands Meteorological Institute, Nether- } \\
\text { lands }\end{array}$ & $\begin{array}{l}\text { No Yes } \\
\text { Swedish Meteorological and Hydrological Institute, }\end{array}$ \\
& RACMO & Yes \\
4 & RCA & Sweden & No \\
5 & REMO & Climate Service Center, Germany & No \\
6 & WRF311A & $\begin{array}{l}\text { CRP - Gabriel Lippmann, Luxembourg } \\
\text { Institut Pierre Simon Laplace / Institut National de }\end{array}$ & No \\
\hline
\end{tabular}




\section{Methodology}

\subsection{Precipitation Indices}

Within the framework of the World Meteorological Organization, the Expert Team on Climate Change Detection and Indices (ETCCDI, http://etccdi. pacificclimate.org/) deals with the definition of climate indices in order to obtain comparable results worldwide. Based on these definitions we here used seasonal precipitation indices derived from daily precipitation amounts (Table 2).

Table 2 Precipitation and derived indices used in this study.

\begin{tabular}{lll} 
ID & Indicator & Units \\
\hline RR & Daily precipitation amount & $\mathrm{mm} / \mathrm{day}$ \\
SDII & Simple day intensity index (mean wet day precipitation) & $\mathrm{mm} / \mathrm{day}$ \\
RR1 & Wet-day frequency & $\mathrm{mm}$ \\
90pWET & 90th percentile on wet days & $\%$ \\
R95pTOT & Percentage of total precipitation contributed by 5\% most rainy days & days \\
CDD & Maximum number of consecutive dry days & \\
\hline
\end{tabular}

SDII, RR and RR1 account for the mean precipitation regime, whereas 90pWET and R95pTOT are considered extreme indices in the sense that they are related to the tails of the probability distribution function, even though they are not associated to rare events. R95pTOT measures the contribution of heavy precipitation events to total precipitation. For Spain, this indicator clearly separates the different extreme regimes of the Atlantic and Mediterranean climates (see, for example, Fig. 10 in Herrera et al, 2012). CDD quantifies dry spells and is linked to precipitation occurrence. CDD and R95pTOT also present different driving mechanisms: CDD is more related to large-scale atmospheric circulation while R95pTOT has a convective origin and depends more on local processes and moisture fluxes (Casanueva et al, 2014).

As recommended by Orlowsky and Seneviratne (2012), 90pWET and R95pTOT were derived over the entire period, while CDD was calculated for each year and season before computing the median for all years.

Figure 1 shows the seasonal observed values for the indices in Table 2 for both regions as represented by APGD011 and Spain011. Note that in both regions, the spatial pattern has a paramount orographic component, especially in winter.

\subsection{Aggregation Procedure}

In order to examine the added value of high resolution simulations at their skillful scale $\left(0.44^{\circ}\right)$, a comparison between the evaluation of the coarse and high resolutions with respect to the coarse resolution observations (Spain044/APGD044) 


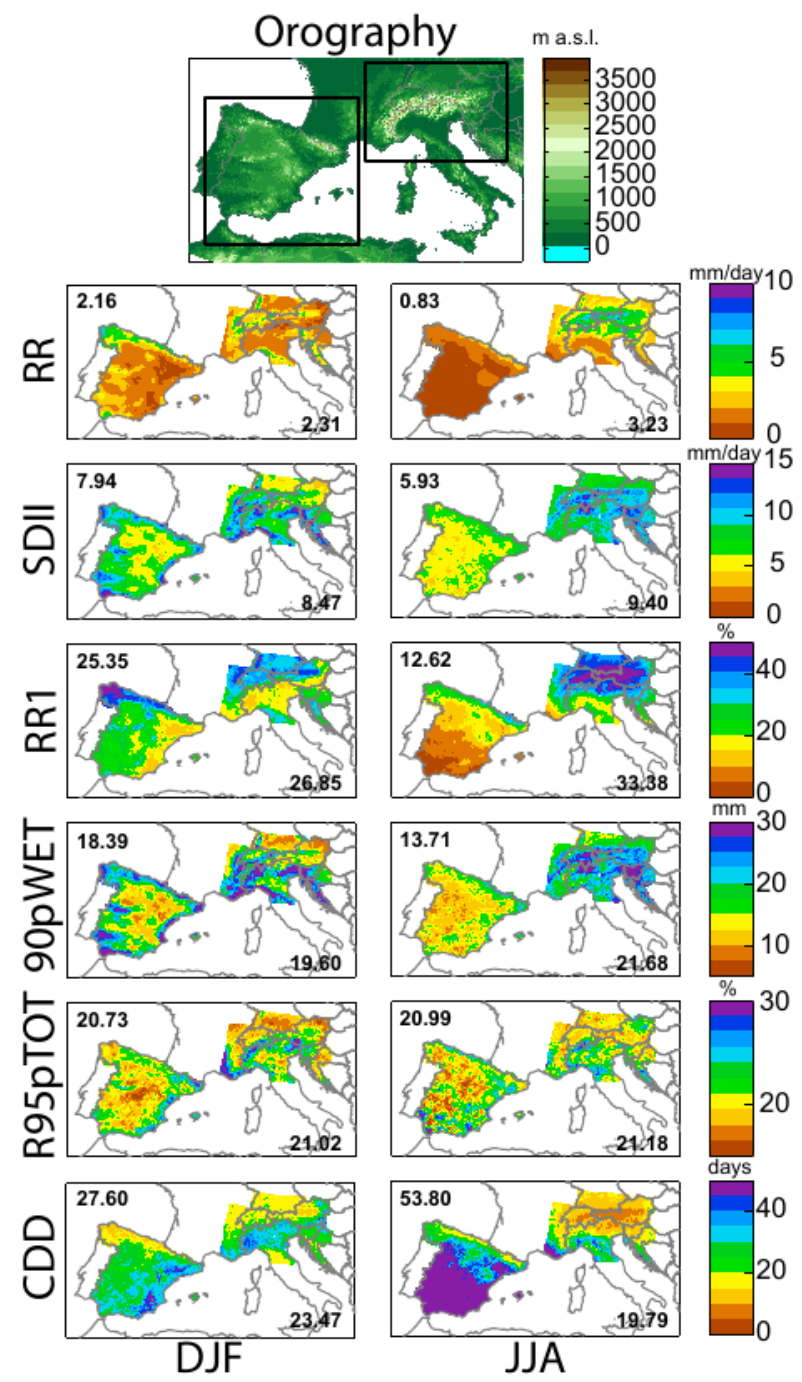

Fig. 1 Seasonal observed distribution of the RR, SDII, RR1, 90pWET, R95pTOT and CDD in winter (left) and summer (right), according to the APGD011/Spain011 datasets. The numbers are the spatial averages in both regions.

was performed. Also, the standard evaluation of the high resolution (i.e. RCMs at $0.11^{\circ}$ with respect to Spain011/APGD011) is shown for illustrative purposes. Thus, from now on we refer to the individual resolutions as three independent datasets: $0.44^{\circ}$ (original simulation), 0.11AGG $\left(0.11^{\circ}\right.$ simulation aggregated to $0.44^{\circ}$ resolution) and $0.11^{\circ}$ (original simulation). By construction, the $0.44^{\circ}$ and $0.11^{\circ}$ EURO-CORDEX grids match each other at the grid cell boundaries, i.e. each $0.44^{\circ}$ grid cell contains exactly $160.11^{\circ}$ grid cells. We 
obtained the aggregated data (0.11AGG) by spatially averaging the grid boxes from the $0.11^{\circ}$ grid that belonged to each $0.44^{\circ}$ grid box (i.e. $160.11^{\circ}$ grid cells were spatially averaged for each $0.44^{\circ}$ grid box). Firstly, we obtained the 011AGG data from the original $0.11^{\circ}$ simulations for each RCM, and secondly we calculated the derived indices from that aggregated data. By means of this procedure we address the added value of the high resolution at its skillful scale (Grasso, 2000), therefore grid-point details (not only related to topography and land-sea mask, but also to better resolved local processes) from the high resolution cannot be discerned, but may be still present after smoothing them onto the coarse resolution. Note that $0.44^{\circ}$ and $0.11 \mathrm{AGG}$ were defined in the same $0.44^{\circ}$ EURO-CORDEX grid and, therefore, they can be directly compared with respect to the same observations (APGD044/Spain044).

The comparison of $0.44^{\circ}$ and $0.11 \mathrm{AGG}$ on the coarse grid can be considered 'fair' since both resolutions are able to resolve the analysed features, however this is not a unique way to assess the added value. Comparing both resolutions on the high resolution grid would penalize the coarse resolution since, even for a perfect simulation, some sub-grid-scale features are missing. According to Prein et al (2015) added value of high resolution is more evident in the evaluation on the high resolution grid since more fine-scale processes are captured. Note that a completely fair comparison would also imply to perform the evaluation exercise at the skillful scale of the coarse resolution experiments (for instance at $4 \times 0.44^{\circ}=1.76^{\circ}$ ), otherwise one resolution is always punished. This, however, would considerably smooth the spatial precipitation fields and also precipitation extremes. We here refrain from doing so but acknowledge that the $0.11^{\circ}$ experiments might be slightly favored in our evaluation setup.

\subsection{Assessment of simple bias correction techniques}

Additionally to the evaluation of the raw RCM outputs, we assessed the results of three simple $\mathrm{BC}$ techniques for precipitation frequency and intensity and evaluated their effect on precipitation indices. The indicators considered in this work depend on precipitation occurrence and/or amount (see Table 2), therefore their biases can be attributed to deficiencies in the precipitation frequency and/or intensity. The three corrections considered were performed seasonally. The first one was based on mean precipitation (considering rainy and non-rainy days), while the others isolated the effect of the precipitation amount (how much) and occurrence (how often), respectively.

First, rainfall data were corrected using a multiplicative scaling factor obtained as the quotient of the observed and simulated spatially averaged precipitation over the specific region (from now on denoted as global scaling, GS):

$$
R R_{G S}=R R_{R C M} \frac{\left\langle\overline{R R_{O B S}}\right\rangle}{\left\langle\overline{R R_{R C M}}\right\rangle}
$$

where $R R_{R C M}$ represents daily RCM precipitation at an individual grid point and the overline and angle brackets represent temporal and spatial averages, 
respectively. This scaling reduces the bulky systematic biases present in every RCM and can be considered as a minimum correction needed at both resolutions. The correction factor is the same for all grid points in a single model, resolution and season, it does not depend on the grid box but on the spatial mean precipitation for the respective analysis domain. To some extent, this bulk correction could mimic a (global) retuning of the model to better fit observations. Note that this correction would work well for overall too dry or too wet models, because it implies constant biases across grid points. As the precipitation spatial pattern presents very high variability and local features, some further corrections were needed at grid point level.

Second, a local scaling $(L S)$ was applied at a grid point level considering the quotient of the observed and simulated wet-day precipitation:

$$
R R_{L S}=R R_{R C M} \frac{S D I I_{O B S}}{S D I I_{R C M}}
$$

Note that these two corrections, GS and LS, do not alter the values of the indicators R95pTOT and CDD.

Third, in addition to these corrections related to the precipitation amount, a correction concerning the precipitation frequency was applied. Many indicators (including those in Table 2) consider the wet day frequency (RR1) in their definitions. Thus an over/underestimation of RR1 would inevitably lead to biases in the derived indicators. A dry (wet) day is defined as a day with precipitation below (above) a given threshold. In the recent literature, the analysis of dry/wet days of observed precipitation and climate model output normally uses subjectively-selected rainfall thresholds (often $0.1 \mathrm{~mm}$ or $1 \mathrm{~mm}$ ) to separate dry and wet days (see e.g. Lázaro et al, 2001; Herrera et al, 2010; Orlowsky and Seneviratne, 2012). Some studies suggest the use of alternative wet/dry day thresholds different to the usually accepted such as $10 \mathrm{~mm}$ (Yoo et al, 2001), 5 and 10mm (Fdez-Arroyabe Hernáez and Martín-Vide, 2012) or the amount exceeded by $96 \%$ of the total rainfall (Aviad et al, 2013). Bärring et al (2006) find an optimal (according to several statistics) wet-day threshold for the whole of Europe of 0.56 and $1.20 \mathrm{~mm}$ (for two model versions of a specific RCM), for the reference threshold of $1 \mathrm{~mm}$ in point observation series. Selecting a single optimal threshold for the whole of Europe is a compromise, since this threshold depends on the location. In this study, we estimated an adjusted wet-day threshold $P^{*}$ at grid point level by selecting the wet-day threshold value in the RCM which matches the observed wet-day frequency (RR1) computed with a $1 \mathrm{~mm}$ threshold:

$$
P^{*}=F_{R C M}^{-1}\left(F_{O B S}(1 m m)\right)
$$

where $F$ is the empirical cumulative distribution function $(\mathrm{CDF})$, so $F_{R C M}$ and $F_{O B S}$ refer to the simulated and observed CDFs, respectively. This value could be different from grid cell to grid cell and was derived separately for each RCM, resolution and season. From now on we denote by $X_{F A}$ a given indicator after the frequency adjustment $(F A)$ is applied, i.e. $P^{*}$ is used for 
the indicator calculation instead of $1 \mathrm{~mm}$. Every precipitation value above this adjusted threshold was assumed to be a wet day in the RCM simulation, otherwise the day was considered dry. After this adjustment in the wet-day threshold, the observed RR1 is perfectly reproduced by the simulation and the contribution of the frequency to the biases in the derived indicators can be isolated.

Bear in mind that FA with very large $\left(P^{*} \gg 1 \mathrm{~mm}\right)$ and close to zero $\left(P^{*} \ll 1 \mathrm{~mm}\right) P^{*}$ values may lead to non reliable results, especially considering its application to impact studies. In the former case, FA and more sophisticated methods adjusting the wet-day frequency - such as quantile mapping (Panofsky and Brier, 1968) - can deal with $P^{*} \gg 1 \mathrm{~mm}$, but at the expense of mapping $P^{*}$ values into $1 \mathrm{~mm}$. For $P^{*}<1 \mathrm{~mm}$, the FA itself is not able to provide an optimal correction since the model is drier than observations and it cannot 'invent' wet days (Bärring et al, 2006). For this reason, sophisticated $\mathrm{BC}$ methods have included additional methods such as the frequency adaptation by randomly sampling the observational distribution into the simulated first bin (Themeßl et al, 2012; Wilcke et al, 2013).

The perfect representation of the wet-day frequency does not necessarily lead to reduced biases in precipitation threshold-dependent indicators, especially in the two cases mentioned above. In the following sections we address the effect of considering $P^{*}$ instead of $1 \mathrm{~mm}$ on the indicators' biases at the different resolutions.

A fourth correction was considered combining the local scaling and the frequency adjustment. Thus, we locally scaled the daily precipitation after adjusting the wet-day threshold (i.e. $Y_{L S}$ where $Y=X_{F A}$, as Schmidli et al, 2006). Results were similar to the LS case, therefore, this correction is not shown in the paper.

\section{Results}

\subsection{Added value in mean precipitation}

Mean precipitation consists of the combination of the daily intensity and wetday frequency. We analyse the contribution of both components separately in order to account for their effect on biases in precipitation-derived indicators (Sect. 4.2). Biases in the precipitation intensity (SDII) are shown in Figures 2 and 3 for winter and summer, respectively, using the $1 \mathrm{~mm}$ threshold for the wet-day definition (same for the wet-day frequency - RR1 - in the supplementary material, Fig.S1-S2). The fourth column represents the difference of the bias on the $0.44^{\circ}$ grid minus $0.11 \mathrm{AGG}$, both in absolute values. Thus, positive differences (greenish colours) show added value of the 0.11AGG and the opposite for negative differences (brownish colours). There is no overall added value of the high resolution simulations aggregated to the $0.44^{\circ}$ grid since, depending on the model and season, biases are smaller for one resolution or the other (in agreement with Kotlarski et al, 2014). Due to the averaging 
procedure, in most cases, 011AGG presents smoother patterns than $0.11^{\circ}$. In winter (Fig. 2), there is a clear orographic pattern in the bias of both regions with some improvements of the high resolution for WRF311A and WRF311F, whereas HIRHAM, RCA and REMO present the highest positive biases at both resolutions for at least one of the regions. In summer (Fig. 3), there is no common spatial bias pattern in both regions. CCLM and RCA considerably reduce biases in the high resolution (especially in the Alpine region) whereas WRF311A and WRF311F present negligible differences between both resolutions. In both seasons, opposite-sign biases at $0.44^{\circ}$ and $0.11 \mathrm{AGG}$ are found in some areas, more noticeable for CCLM in winter and RCA and REMO (also HIRHAM for Spain) in summer. This means that the same parameterizations with different resolutions lead to different precipitation intensities and also different spatial patterns. REMO stands out in summer, since both regions present mainly wet biases at $0.44^{\circ}$, but dry biases predominate at $0.11^{\circ}$ and, therefore, at 011AGG. Apparently, some physical schemes seem more resolution dependent than others (Déqué et al, 2005). Further research about the sensitivity of seasonal biases to the different schemes (see e.g. García-Díez et al, 2013) should be performed in the specific RCMs and resolutions. Note also the patchy spatial pattern in HIRHAM011, RCA011 and REMO011 with strong, opposite biases in nearby grid boxes, i.e. there is not a gradual change across the zero bias between opposite sign biases. For HIRHAM and REMO this could be due to the use of non-smoothed orography (see the fourth column in Table 1). Previous studies have also associated biases to the excessively smoothed (Shkolnik and Efimov, 2013) or non-smoothed topography (Polanski et al, 2010), being the orography another factor to take into account in RCMs evaluation.

Precipitation occurrence is characterized in terms of the wet-day frequency, which depends on the particular threshold (e.g. $1 \mathrm{~mm}$ ) used to define a wet day. Figure 4 shows the q-q plot for three selected grid points in RCA011 for winter daily precipitation (black crosses). The vertical line corresponds to $1 \mathrm{~mm}$ in the observations. Therefore the intersection with the q-q plot provides the adjusted threshold equivalent to $1 \mathrm{~mm}$ in the observations $\left(P^{*}\right.$, see Eq.3). On the left, the model overestimates the wet-day frequency and $P^{*}$ is around $16 \mathrm{~mm}$ (intersection of black crosses with the vertical line). The center panel corresponds to a grid point where $P^{*}$ approximates $1 \mathrm{~mm}$. On the right, the model presents more dry days than observed $\left(P^{*}<1 \mathrm{~mm}\right)$. This figure illustrates that adjusted thresholds are in some cases very far from $1 \mathrm{~mm}$ (left), but also close to $0 \mathrm{~mm}$ (right). Only the points with $P^{*} \approx 1 \mathrm{~mm}$ (center) would work well with the usually accepted $1 \mathrm{~mm}$ threshold.

When defining wet days using $P^{*}$ instead of $1 \mathrm{~mm}$, precipitation intensity (SDII) is also altered, since it is defined as the mean of the wet-day precipitation. For $P^{*}>1 \mathrm{~mm}$, SDII would be shifted towards higher values, since low-precipitation values in the range $\left(1 \mathrm{~mm}, P^{*}\right)$ are considered dry days. For $P^{*}<1 \mathrm{~mm}$, dry SDII biases are expected due to the contribution of many close-to-zero precipitation values regarded as wet days. 
Figures 5 and 6 show the spatial pattern of $P^{*}$ computed according to Eq. 3 360 for winter and summer, respectively. In winter, $P^{*}$ is higher in places with 1 complex orography (the Alps and Pyrenees) and lower in lowlands, especially for HIRHAM and RCA. In Spain, $P^{*}$ does not reach as large values as in the Alpine region. Smaller $P^{*}$ is also found in summer, with many zero or close to zero values (e.g. CCLM, HIRHAM, RCA especially in Spain). Notice that the definition of wet days depends on $P^{*}$ and, therefore, the indicators (SDII, CDD, 90pWET and R95pTOT) are expected to change as the threshold $P^{*}$ changes. Hence, the evaluation results depend on the value which is chosen as the wet-day threshold, which is usually subjectively adopted (e.g. commonly $1 \mathrm{~mm}$ or $0.1 \mathrm{~mm}$ ) or adjusted with the observations, as done in this study.

Thus far, EURO-CORDEX RCMs present biases in SDII and RR1 at both resolutions that will propagate to the derived indices. BC methods allow to statistically correct these deviations, but the underlying physical misrepresentations will remain and may still affect higher-order moments of the corrected variables. Large $P^{*}$ also affects sophisticated BC methods. For instance, $P^{*}$ (Figs. 5 and 6) determines the highest (or lowest) value which is mapped into $1 \mathrm{~mm}$ when applying a quantile mapping (Panofsky and Brier, 1968) using the standard $1 \mathrm{~mm}$ wet-day threshold. The patchy spatial pattern shown before for SDII (Figs. 2 and 3) is also found in the HIRHAM011, RCA011 and REMO011 adjusted thresholds (Figs. 5 and 6). This may lead to spatial inconsistencies in sophisticated BC techniques, since two nearby grid points can have very different $P^{*}$. These aspects constitute a theoretical discussion and need to be proven and analysed in further studies. No patchy spatial pattern is noticeable at the 011AGG scale, due to the underlying averaging procedure. Therefore, corrections in the frequency should be accomplished at the coarse scale, where no spatial inconsistencies are found and $0.44^{\circ}$ and 011AGG present comparable results in terms of spatial coherence. Conversely, at $0.11^{\circ}$ resolution, WRF and CCLM present more spatially coherent and smoothed patterns and RACMO stands out with $P^{*}$ close to $1 \mathrm{~mm}$, especially over large parts of Spain.

\subsection{Added value in precipitation derived indicators}

We now examine the added value of the high resolution experiments for precipitationderived indicators (low versus high resolution) and account for the effect of the biases in SDII and RR1 on derived indicators by applying BC methods at both resolutions (raw versus corrected data). All indicators considered (Table 2) depend on the wet-day threshold. Thus, they are calculated with the $1 \mathrm{~mm}$ and $P^{*}$ (FA, Sect.3.3). 90pWET is also affected by the precipitation amount, therefore GS and LS corrections are performed. Biases for 90pWET and CDD (relative) and R95pTOT (absolute) are obtained for the raw and the corrected data for $0.44^{\circ}$ and 011AGG. 
Results for the 90th percentile on wet days (90pWET) are summarized in Figure 7. The 'original' label refers to the case when no correction is performed, i.e. without any scaling and taking $1 \mathrm{~mm}$ as the wet-day threshold. Global scaling does not lead to overall conclusions, it usually reduces very high biases but deteriorates smaller ones. Local scaling strongly reduces the biases, along with their spatial variability, in every RCM and resolution. This results in individual grid-point biases of similar magnitude at both resolutions (median markers close to zero, and similar-sized boxes). This means that any improvement of a resolution with respect to the other before the correction does not necessarily lead to an improvement after the local scaling since biases become comparable for both resolutions (see e.g. WRF331F in Spain). Less frequently, an improvement before the correction remains (see e.g. RCA in Spain) or turns into a deterioration (see e.g. RACMO in Spain in winter) after the LS, although these are subtle changes. The application of the frequency adjustment (using $P^{*}$ as the wet-day threshold) leads to similar biases to those in the original case (using $1 \mathrm{~mm}$ wet-day threshold). Notice that especially for $P^{*}>1 \mathrm{~mm}$, changing the threshold yields slightly different percentiles, while the scaling changes the indicator more rapidly (see dots in Fig. 4, representing the deciles from the wet day distribution for the original (black), FA (blue) and LS (red)).

Regarding the added value, neither the original nor the corrected data lead to an overall improvement of one resolution against the other since results are similar for both resolutions and the best performance is obtained for $0.44^{\circ}$ or 0.11AGG depending on the specific case.

\section{R95pTOT}

Figure 8 summarizes the absolute biases for the contribution of very wet days (R95pTOT). In winter, negligible differences are found between resolutions in both regions and few changes are obtained after the frequency adjustment. The correction can cause a small improvement (e.g. RCA in Spain) or deterioration (e.g. CCLM in the Alpine region). Hence the R95pTOT involves more processes (related to precipitation intensity) responsible for the biases that cannot be attributed to the wet-day frequency. In summer, the $0.44^{\circ}$ simulation in the original case in the Alpine region is slightly better or does not differ much from 0.11AGG except for CCLM. After the frequency adjustment CCLM, HIRHAM and RCA biases increase dramatically on the coarse resolution. This could be due to the very low $P^{*}$ values (see Fig. 6), leading to an increase of this indicator and therefore to very large positive biases.

$C D D$

For the number of consecutive dry days (CDD, Fig. 9) in winter the frequency adjustment tends to reduce biases and diminish the differences between reso- 
lutions in Spain, but slightly benefits $0.11 \mathrm{AGG}$ in the Alpine region. Relative biases for summer CDD are very large for CCLM and HIRHAM at both resolutions - related to their large negative biases in the frequency (see Fig.S2)-, showing their difficulties to properly represent the lower part of the precipitation distribution and the temporal coherence. The frequency adjustment substantially reduces these biases, meaning that the spells are better captured when the wet-day frequency is adjusted to the observed one. Unlike CCLM and HIRHAM, RCA does not reduce its large bias in summer in the Alpine region after the frequency adjustment and a large negative bias remains. This is due to the zero values of the wet-day adjusted thresholds that are apparent over approximately one third of the Alpine domain (black grid boxes in Figure 6). Since the wet-day threshold is exactly zero, there are no dry spells in these grid boxes, leading to large negative biases of CDD.

\section{Joint discussion}

The above results show that $90 \mathrm{pWET}$ is more sensitive to the intensity whereas the CDD is affected by the wet-day threshold. Thus, they also present different sensitivities to the local scaling and frequency adjustment. On the one hand, the frequency adjustment slightly changes the 90pWET (i.e. changing the threshold yields a slightly different percentile). This means that the precipitation frequency (i.e. the lower tail of the precipitation distribution) does not have a systematic implication for the upper percentiles (i.e. upper tail based indices). In some models the correction can either make it slightly better or worse, but in very dry models the correction can even strongly deteriorate it (e.g. CCLM and RCA in summer). Precipitation intensity, however, plays a major role in 90pWET; when the precipitation distribution is scaled by SDII, the upper percentiles are scaled too (in agreement with Benestad et al, 2012). On the other hand, the frequency adjustment considerably reduces CDD biases. Once the observed and simulated wet-day frequencies are equal, the RCM better captures the dry spell durations. As mentioned before, in some cases (see e.g. RCA in summer in the Alpine region in Fig. 9) frequency adjustment does not reduce CDD biases because the time series autocorrelation and persistence (and therefore occurrence) of specific situations are not well represented by the model and the correction is not able to resolve this. For this reason, the frequency adjustment deteriorates biases in that example for 90pWET and R95pTOT too. Unlike 90pWET and CDD, which are more sensitive to the intensity and frequency, respectively, for R95pTOT the frequency adjustment can either deteriorate or not affect the results. The definition of R95pTOT includes both the intensity and the frequency, and correcting for biases of these two aspects can have converse effects.

As shown in Figures 7, 8 and 9, the selected indicators are affected by very low summer $P^{*}$. In this case, 90pWET (CDD) is lower (higher) because of too many zero-precipitation values. R95pTOT is based on a lower 95th percentile, resulting in a higher quotient of the contribution of very wet days relative to the total wet-day precipitation amount. This is a limitation in the 
frequency adjustment; when RCMs are too dry, an optimal threshold does not necessarily lead to an improvement because the correction cannot 'invent' wet days (Bärring et al, 2006). This should be carefully examined since basic bias correction techniques are not able to solve this problem and more sophisticated techniques are required to deal with this issue (Themeßl et al, 2012; Wilcke et al, 2013).

The correction methods used in this study are not able to correct all indicators at a time. The precipitation occurrence affects the indices related to spells rather than the upper-tail percentiles, which are more influenced by precipitation intensity. That result suggests that there is not a single optimal, best way of bias correcting RCMs, since methods adjusting the frequency better represent the CDD, but can deteriorate the upper tail percentiles. Further analyses should be performed to quantify this result in more sophisticated bias correction methods combining several corrections. Note that we use the same period for the calibration and validation of the BC methods, since we validate aspects that are not directly tackled by the $\mathrm{BC}$ procedure. Validation results might look worse if an independent validation period would be chosen.

\subsection{Added value and bias correction effect on the spatial pattern}

The correction methods applied in the previous section preserve the temporal structure of the data and in this section we analyse their effect on the spatial pattern. We only show results for the $0.44^{\circ}$ and $0.11 \mathrm{AGG}$ data sets, since these can be directly compared against the same observations.

The ability to represent the spatial structure is summarized by means of Taylor (2001) diagrams (Fig. 10). These show several spatial scores at a time: spatial Pearson correlation coefficient (r), Centered Root Mean Squared Difference (RMSD), standard deviation (std) and biases of spatial averages (bias). Arrows join, for a given RCM, the 0.44 score (squares) with the 011AGG (circles). Therefore, arrows pointing towards the observational reference indicate that the high-resolution runs (011AGG) perform better than the coarse ones $\left(0.44^{\circ}\right)$. To summarize the added value of $0.11 \mathrm{AGG}$, the bars in the right panels show the number of RCMs (from 0 to 7 ) in which the 0.11AGG improves with respect to the $0.44^{\circ}$ resolution, in terms of the four statistics shown in the Taylor diagram. In these barplots, the numbers of the right Y-axis show the statistical significance of the existence of added value, obtained by a Z-test for proportions. The results are statistically significant only when 6 or $7 \mathrm{RCMs}$ (and symmetrically for 0 and 1) out of 7 improve upon the $0.44^{\circ}$ resolution runs. For the raw RCM output (Fig. 10, first row), high-resolution RCMs generally perform better than the coarse counterparts, especially in terms of $\mathrm{r}$ and RMSD (bias and std are not conclusive). After the corrections (Fig. 10, second row), all the RCMs present similar validation scores for CDD and 90pWET regardless of the resolution (the squares are close to the circles). The proportion of the 0.11AGG RCMs that improves with respect to the coarse ones is not statistically significant after the corrections. R95pTOT deteriorates with the 
frequency adjustment except for CCLM and RACMO (labels 1 and 3, respectively) since these two RCMs present $P^{*}$ close to $1 \mathrm{~mm}$ (as shown in Fig.5). This degradation after applying the correction was also shown in the previous section, meaning that this indicator is not favoured by the frequency adjustment. The results for summer and for Spain in both seasons lead to similar conclusions and are included in the supplementary material (Fig.S3-S5).

\section{Conclusions}

This paper evaluates daily precipitation characteristics in the ERA-Interimdriven EURO-CORDEX RCM ensemble. Experiments at both $0.11^{\circ}$ and $0.44^{\circ}$ horizontal resolution are considered, and the potential added value of the $0.11^{\circ}$ simulations is addressed. For this purpose, high-resolution RCMs are regridded onto the coarse grid by grid cell aggregation (0.11AGG). The analysis is performed in two regions of Europe where high quality gridded observational data sets are available (continental Spain and the Alpine region) considering mean precipitation and derived indicators (90th percentile on wet days - 90pWET - , contribution of the very wet days - R95pTOT - and number of consecutive dry days - CDD-).

In terms of seasonal biases we find only limited evidence for an added value of the higher resolution in the precipitation intensity, wet-day frequency and derived indicators, since results depend on the RCM, season and indicator and small differences rather randomly favour the $0.44^{\circ}$ or the $0.11 \mathrm{AGG}$ resolutions. We find added value of the high resolution simulations in the spatial pattern (especially in correlation and RMSD). To adequately represent daily precipitation statistics, bias correction techniques are needed at both resolutions. Nevertheless, after applying simple bias correction techniques the proportion of the 0.11AGG RCMs that improves with respect to the coarse ones is not statistically significant and there are negligible differences between resolutions.

Note that we only partly address the potential added value, since high resolution simulations are not only used with the intention to improve the larger scale processes and features but also in order to provide better local information (i.e. the local departures of the $0.11^{\circ}$ relative to the $0.11 \mathrm{AGG}$ or $0.44^{\circ}$ simulation results should be better than a random information). Our validation on the coarse grid can be considered 'fair' because it compares features resolved by both resolutions, however it is not the unique way to assess the added value (Di Luca et al, 2015). Pursuing a fairer comparison between resolutions would also require the retuning of the high resolution simulations and the consideration of the $0.44^{\circ}$ simulations at their skillful scale. Prein et al (2015) claim that the added value of the high resolution is more evident when the comparison is performed on the high resolution grid but acknowledge that this procedure benefits the high resolution runs.

The present work and Prein et al (2015) try to shed light on the added value issue by analysing different precipitation aspects taking into account precipitation-derived indices related to the intensity, frequency and extremes, 
and from daily to sub-daily scales. As such, both works are complementary to each other. Both show the benefits of the high resolution in spatial patterns, however we find no statistically significant results after bias correction. Prein et al (2015) identify Spain and the Alpine area as the regions with largest netimproved-area fractions (i.e. fraction of grid boxes in which more than $75 \%$ of the high resolution simulations improve on the coarse counterparts). However that fraction is never higher than $50 \%$ of improvement, meaning that more than half of the grid points in each region is deteriorated or (in most of the cases) is similar in both resolutions. From our results, added value of the high resolution on seasonal mean biases depends on the indicator, RCM and season and the best performance is obtained for $0.44^{\circ}$ or $0.11 \mathrm{AGG}$ depending on the specific case. Both studies are focused on different indicators for extreme precipitation, thus making it difficult to intercompare them. While Prein et al (2015) find also added value in other aspects such as the sub-daily scale, we focus on the added value of bias corrected simulations, which could be of great interest for the impact community.

We apply three simple bias correction methods based on the correction of the first moments of the precipitation distribution. First, results show that scaling by the quotient between observed and simulated spatial mean precipitation is not enough to reduce biases in the 90pWET. Second, the local scaling with the wet-day intensity reduces the 90pWET biases dramatically (i.e. correcting the mean also corrects the percentiles) and makes both resolutions comparable after the correction. Third, the frequency adjustment improves the lower part of the probability distribution function (better representation of the CDD) but it deteriorates the upper tails (worse or negligible changes in the 90pWET and R95pTOT). Therefore, these corrections do not show an overall improvement which strongly indicates that there is no single optimal way to correct for RCM biases. Users should make a choice for one bias correction method or the other depending on the precipitation metric being assessed (e.g. local scaling is more efficient for percentiles and the frequency adjustment for dry spells), but being aware that the same method can at the same time deteriorate another feature of the distribution. This emphasizes the need to investigate more sophisticated bias correction methods that correct several aspects at a time.

Large biases remain in the derived indicators after the frequency adjustment when the adjusted threshold is zero (see e.g. CCLM in Spain and RCA in the Alpine region in summer). Bias correction has traditionally relied on the assumption that models produce more rainy days than the reference observations and these methods work well for finding optimized thresholds when the climate model overestimates the number of wet days by frequently simulating light rainfall. However, the procedure cannot improve the opposite situation because it cannot 'invent' wet days if the model is too dry (in agreement with Bärring et al, 2006). This problem is very noticeable in summer and further research is needed (e.g., along the lines of the frequency adaptation from Themeßl et al, 2012) since it is not possible to fully solve it with the basic bias correction techniques applied in the present work. 
Sophisticated bias correction methods are well prepared to solve any problem in the precipitation Probability Density Function. In this work we identify some shortcomings (e.g. deficiencies in the representation of the wet-day frequency) in specific RCM simulations that may have implications for the suitability for such methods. For instance, some RCMs at $0.11^{\circ}$ resolution present very high $P^{*}$ (caused by strong biases in the precipitation frequency). Some sophisticated methods (e.g. quantile mapping) map this large $P^{*}$ onto $1 \mathrm{~mm}$ and values in the range $\left(1 \mathrm{~mm}, P^{*}\right)$ onto dry days. There are also spatial inconsistencies in some models at the high resolution which might be related to instabilities due the use of non-smoothed orographies and a spatial displacement of precipitation structures (Maraun and Widmann, 2015). This could give unreliable results after applying single-site bias correction methods (i.e. point-wise methods, not considering the spatial coherence).

This study gives insight into the daily precipitation statistics in the EUROCORDEX RCM ensemble by analysing each ensemble member individually. Better agreement with the observations is usually found when ensemble averages are validated and, moreover, this improves when only the best performing models are considered (Herrera et al, 2010). Bearing this in mind more efforts should be devoted towards the improvement of the individual models in order to avoid very strong biases. For this purpose, further research about the impact of different parameterization schemes on seasonal biases as García-Díez et al (2013) should be performed for the specific RCMs.

Acknowledgements The authors are grateful to Prof. C. Schär for his helpful comments and E. van Meijgaard for making available the RACMO model data. We acknowledge the observational data providers. Calculations for WRF311F were made using the TGCC super computers under the GENCI time allocation GEN6877. The WRF331A from CRP-GL (now LIST) was funded by the Luxembourg National Research Fund (FNR) through grant FNR C09/SR/16 (CLIMPACT). The KNMI-RACMO2 simulations were supported by the Dutch Ministry of Infrastructure and the Environment. The CCLM and REMO simulations were supported by the Federal Ministry of Education and Research (BMBF) and performed under the Konsortial share at the German Climate Computing Centre (DKRZ). The CCLM simulations were furthermore supported by the Swiss National Supercomputing Centre (CSCS) under project ID s78. Part of the SMHI contribution was carried out in the Swedish Mistra-SWECIA programme founded by Mistra (the Foundation for Strategic Environmental Research). This work is supported by CORWES (CGL2010-22158-C02) and EXTREMBLES (CGL2010-21869) projects funded by the Spanish R\&D programme and the European COST ACTION VALUE (ES1102). A. C. thanks the Spanish Ministry of Economy and Competitiveness for the funding provided within the FPI programme (BES2011-047612 and EEBB-I-13-06354). We also thank two anonymous referees for their useful comments that helped to improve the original manuscript.

\section{References}

Argüeso D, Evans JP, Fita L (2013) Precipitation bias correction of very high resolution regional climate models. Hydrology and Earth System Sciences 17(11):4379-4388, DOI 10.5194/hess-17-4379-2013 
Aviad Y, Kutiel H, Lavee H (2013) Empirical models of rain-spells characteristics - A case study of a Mediterranean-arid climatic transect. Journal of Arid Environments 97:84-91, DOI 10.1016/j.jaridenv.2013.05.015

Bärring L, Holt T, Linderson M, Radziejewski M, Moriondo M, Palutikof JP (2006) Defining dry/wet spells for point observations, observed area averages, and regional climate model gridboxes in Europe. Climate Research 31(1):35-49, DOI 10.3354/cr031035

Bellprat O, Kotlarski S, Lüthi D, Schär C (2013) Physical constraints for temperature biases in climate models. Geophysical Research Letters 40(15):4042-4047, DOI 10.1002/grl.50737

Benestad RE, Nychka D, Mearns LO (2012) Spatially and temporally consistent prediction of heavy precipitation from mean values. Nature Climate Change 2(7):544-547, DOI 10.1038/NCLIMATE1497

Boberg F, Christensen JH (2012) Overestimation of Mediterranean summer temperature projections due to model deficiencies. Nature Clim Change 2(6):433-436, DOI 10.1038/nclimate1454

Casanueva A, Herrera S, Fernández J, Frías M, Gutiérrez J (2013) Evaluation and projection of daily temperature percentiles from statistical and dynamical downscaling methods. Natural Hazards and Earth System Sciences 3:2089-2099, DOI 10.5194/nhess-13-2089-2013

Casanueva A, Rodríguez-Puebla C, Frías M, González-Reviriego F (2014) Variability of extreme precipitation over Europe and its relationships with teleconnection patterns. Hydrology and Earth System Sciences 18:1-17, DOI 10.5194/hess-18-709-2014

Chan SC, Kendon EJ, Fowler HJ, Blenkinsop S, Ferro CAT, Stephenson DB (2013) Does increasing the spatial resolution of a regional climate model improve the simulated daily precipitation? Climate Dynamics 41(5-6):14751495, DOI 10.1007/s00382-012-1568-9

Christensen JH, Machenhauer B, Jones RG, Schar C, Ruti PM, Castro M, Visconti G (1997) Validation of present-day regional climate simulations over Europe: LAM simulations with observed boundary conditions. Climate Dynamics 13(7-8):489-506

Christensen JH, Boberg F, Christensen OB, Lucas-Picher P (2008) On the need for bias correction of regional climate change projections of temperature and precipitation. Geophysical Research Letters 35(20):L20,709, DOI 10.1029/2008GL035694

Dee DP, Uppala SM, Simmons AJ, Berrisford P, Poli P, Kobayashi S, Andrae U, Balmaseda MA, Balsamo G, Bauer P, Bechtold P, Beljaars ACM, van de Berg L, Bidlot J, Bormann N, Delsol C, Dragani R, Fuentes M, Geer AJ, Haimberger L, Healy SB, Hersbach H, Hólm EV, Isaksen L, Kållberg P, Köhler M, Matricardi M, McNally AP, Monge-Sanz BM, Morcrette J, Park B, Peubey C, de Rosnay P, Tavolato C, Thépaut JN, Vitart F (2011) The ERA-Interim reanalysis: configuration and performance of the data assimilation system. Quart J R Meteorol Soc 137:553-597

Déqué M, Jones RG, Wild M, Giorgi F, Christensen JH, Hassell DC, Vidale PL, Rockel B, Jacob D, Kjellstrm E, Castro Md, Kucharski F, Hurk Bvd 
(2005) Global high resolution versus limited area model climate change projections over Europe: quantifying confidence level from PRUDENCE results. Climate Dynamics 25(6):653-670, DOI 10.1007/s00382-005-0052-1

Di Luca A, de Ela R, Laprise R (2015) Challenges in the Quest for Added Value of Regional Climate Dynamical Downscaling. Current Climate Change Reports 1(1):10-21, DOI 10.1007/s40641-015-0003-9

Durman CF, Gregory JM, Hassell DC, Jones RG, Murphy JM (2001) A comparison of extreme European daily precipitation simulated by a global and a regional climate model for present and future climates. QJR Meteorol Soc 127(573):1005-1015, DOI 10.1002/qj.49712757316

Fdez-Arroyabe Hernáez P, Martín-Vide J (2012) Regionalization of the probability of wet spells and rainfall persistence in the Basque Country (northern Spain). International Journal of Climatology 32(12):1909-1920, DOI $10.1002 /$ joc. 2405

Fernández J, Montávez JP, Sáenz J, González-Rouco JF, Zorita E (2007) Sensitivity of MM5 mesoscale model to physical parameterizations for regional climate studies: Annual cycle. J Geophys Res 112:D04,101, doi:10.1029/2005JD00664

Feser F, Rockel B, von Storch H, Winterfeldt J, Zahn M (2011) Regional climate models add value to global model data: a review and selected examples. Bulletin of the American Meteorological Society 92(9):1181-1192

Frei C, Christensen JH, Déqué M, Jacob D, Jones RG, Vidale PL (2003) Daily precipitation statistics in regional climate models: Evaluation and intercomparison for the European Alps. Journal of Geophysical Research: Atmospheres 108(D3):4124, DOI 10.1029/2002JD002287

García-Díez M, Fernández J, Fita L, Yagüe C (2013) Seasonal dependence of WRF model biases and sensitivity to PBL schemes over Europe. Quarterly Journal of the Royal Meteorological Society 139:501-514, DOI 10.1002/qj. 1976

García-Díez M, Fernández J, Vautard R (2015) An RCM multi-physics ensemble over Europe: multi-variable evaluation to avoid error compensation. Clim Dyn pp 1-16, DOI 10.1007/s00382-015-2529-x

Gibelin AL, Déqué M (2003) Anthropogenic climate change over the Mediterranean region simulated by a global variable resolution model. Climate Dynamics 20(4):327-339, DOI 10.1007/s00382-002-0277-1

Giorgi F (2006) Regional climate modeling: Status and perspectives. Journal de Physique IV (Proceedings) 139(1):101-118, DOI 10.1051/jp4:2006139008

Giorgi F, Jones C, Asrar G (2009) Addressing climate information needs at the regional level: the CORDEX framework. WMO Bulletin 58(3):175-183

Grasso L (2000) The differentiation between grid spacing and resolution and their application to numerical modeling. Bulletin of the American Meteorological Society 81:579580

Herrera S, Fita L, Fernndez J, Gutirrez JM (2010) Evaluation of the mean and extreme precipitation regimes from the ENSEMBLES regional climate multimodel simulations over Spain. J Geophys Res 115(D21):D21,117, DOI 10.1029/2010JD013936 
Herrera S, Gutiérrez J, Ancell R, Pons M, Frías M, Fernández J (2012) Development and analysis of a 50 year high resolution daily gridded precipitation dataset over Spain (Spain02). International Journal of Climatology DOI $10.1002 /$ joc. 2256

Herrera S, Fernández J, Gutiérrez (2015) Update of the Spain02 gridded observational dataset for EURO-CORDEX evaluation: Assessing the effect of the interpolation methodology. International Journal of Climatology , in print, DOI 10.1002/joc.4391

Hofstra N, Haylock M, New M, Jones PD (2009) Testing E-OBS European high-resolution gridded data set of daily precipitation and surface temperature. Journal of Geophysical Research: Atmospheres 114(D21), DOI 10.1029/2009JD011799

Isotta FA, Frei C, Weilguni V, Perčec Tadić M, Lassègues P, Rudolf B, Pavan V, Cacciamani C, Antolini G, Ratto SM, Munari M, Micheletti S, Bonati V, Lussana C, Ronchi C, Panettieri E, Marigo G, Vertačnik G (2013) The climate of daily precipitation in the Alps: development and analysis of a high-resolution grid dataset from pan-Alpine rain-gauge data. International Journal of Climatology DOI 10.1002/joc.3794

Jacob D, Bärring L, Christensen OB, Christensen JH, de Castro M, Déqué M, Giorgi F, Hagemann S, Lenderink G, Rockel B, Sanchez E, Schär C, Seneviratne SI, Somot S, van Ulden A, van den Hurk B (2007) An intercomparison of regional climate models for Europe: model performance in present-day climate. Climatic Change 81:31-52

Jacob D, Petersen J, Eggert B, Alias A, Christensen OB, Bouwer LM, Braun A, Colette A, Déqué M, Georgievski G, Georgopoulou E, Gobiet A, Menut L, Nikulin G, Haensler A, Hempelmann N, Jones C, Keuler K, Kovats S, Kröner N, Kotlarski S, Kriegsmann A, Martin E, Meijgaard Ev, Moseley C, Pfeifer S, Preuschmann S, Radermacher C, Radtke K, Rechid D, Rounsevell M, Samuelsson P, Somot S, Soussana JF, Teichmann C, Valentini R, Vautard R, Weber B, Yiou P (2014) EURO-CORDEX: new high-resolution climate change projections for european impact research. Reg Environ Change 14(2):563-578, DOI 10.1007/s10113-013-0499-2

Jerez S, Montavez JP, Jimenez-Guerrero P, Gomez-Navarro JJ, Lorente-Plazas R, Zorita E (2012) A multi-physics ensemble of present-day climate regional simulations over the Iberian Peninsula. Climate Dynamics pp 1-24, DOI 10.1007/s00382-012-1539-1

Kendon EJ, Roberts NM, Senior CA, Roberts MJ (2012) Realism of rainfall in a very high-resolution regional climate model. Journal of Climate 25(17):5791-5806, DOI 10.1175/JCLI-D-11-00562.1

Kotlarski S, Keuler K, Christensen OB, Colette A, Déqué M, Gobiet A, Goergen K, Jacob D, Lüthi D, van Meijgaard E, Nikulin G, Schär C, Teichmann C, Vautard R, Warrach-Sagi K, Wulfmeyer V (2014) Regional climate modeling on european scales: a joint standard evaluation of the EURO-CORDEX RCM ensemble. Geosci Model Dev 7(4):1297-1333, DOI 10.5194/gmd-7-1297-2014 
Lázaro R, Rodrigo FS, Gutiérrez L, Domingo F, Puigdefábregas J (2001) Analysis of a 30-year rainfall record (1967-1997) in semi-arid SE Spain for implications on vegetation. Journal of Arid Environments 48(3):373-395, DOI 10.1006/jare.2000.0755

van der Linden P, Mitchell J (eds) (2009) ENSEMBLES: Climate Change and its Impacts: Summary of research and results from the ENSEMBLES project. Met Office Hadley Centre, FitzRoy Road, Exeter EX1 3PB, UK

Maraun D, Widmann M (2015) The representation of location by regional climate models in complex terrain. Hydrol Earth Syst Sci Discuss 12(3):30113028, DOI 10.5194/hessd-12-3011-2015

Nikulin G, Kjellstrom E, Hansson U, Strandberg G, Ullerstig A (2011) Evaluation and future projections of temperature, precipitation and wind extremes over Europe in an ensemble of regional climate simulations. Tellus Series aDynamic Meteorology and Oceanography 63(1):41-55

Orlowsky B, Seneviratne SI (2012) Global changes in extreme events: regional and seasonal dimension. Climatic Change 110(3-4):669-696, DOI 10.1007/ s10584-011-0122-9

Panofsky HA, Brier GW (1968) Some applications of statistics to meteorology. University Park : Penn. State University, College of Earth and Mineral Sciences

Piani C, Haerter JO, Coppola E (2010) Statistical bias correction for daily precipitation in regional climate models over Europe. Theoretical and Applied Climatology 99(1-2):187-192, DOI 10.1007/s00704-009-0134-9

Polanski S, Rinke A, Dethloff K (2010) Validation of the HIRHAMsimulated Indian summer monsoon circulation. Advances in Meteorology 2010:e415,632, DOI 10.1155/2010/415632

Prein AF, Holland GJ, Rasmussen RM, Done J, Ikeda K, Clark MP, Liu CH (2013) Importance of regional climate model grid spacing for the simulation of heavy precipitation in the Colorado headwaters. Journal of Climate 26(13):4848-4857, DOI 10.1175/JCLI-D-12-00727.1

Prein AF, Gobiet A, Truhetz H, Keuler K, Goergen K, Teichmann C, Fox Maule C, van Meijgaard E, Déqué M, Nikulin G, Vautard R, Colette A, Kjellström E, Jacob D (2015) Precipitation in the EURO-CORDEX 0.11 and $0.44^{\circ}$ simulations: high resolution, high benefits? Climate Dynamics DOI $10.1007 / \mathrm{s} 00382-015-2589-\mathrm{y}$

Pryor SC, Nikulin G, Jones C (2012) Influence of spatial resolution on regional climate model derived wind climates. J Geophys Res 117(D3):D03,117, DOI 10.1029/2011JD016822

Roeckner E, Brokopf R, Esch M, Giorgetta M, Hagemann S, Kornblueh L, Manzini E, Schlese U, Schulzweida U (2006) Sensitivity of simulated climate to horizontal and vertical resolution in the ECHAM5 atmosphere model. Journal of Climate 19(16):3771-3791

Schmidli J, Frei C, Vidale PL (2006) Downscaling from GCM precipitation: a benchmark for dynamical and statistical downscaling methods. International Journal of Climatology 26(5):679-689, DOI 10.1002/joc.1287 
Shkolnik IM, Efimov SV (2013) Cyclonic activity in high latitudes as simulated by a regional atmospheric climate model: added value and uncertainties. Environmental Research Letters 8(4):045,007, DOI 10.1088/1748-9326/8/ $4 / 045007$

Taylor KE (2001) Summarizing multiple aspects of model performace in a single diagram. J Geophys Res 106(D7):7183-7192

Teichmann C, Eggert B, Elizalde A, Haensler A, Jacob D, Kumar P, Moseley C, Pfeifer S, Rechid D, Remedio AR, Ries H, Petersen J, Preuschmann S, Raub T, Saeed F, Sieck K, Weber T (2013) How does a regional climate model modify the projected climate change signal of the driving GCM: A study over different CORDEX regions using REMO. Atmosphere 4(2):214236, DOI 10.3390/atmos4020214

Themeßl MJ, Gobiet A, Heinrich G (2012) Empirical-statistical downscaling and error correction of regional climate models and its impact on the climate change signal. Climatic Change 112(2):449-468, DOI 10.1007/ s10584-011-0224-4

Vautard R, Gobiet A, Jacob D, Belda M, Colette A, Déqué M, Fernández J, García-Díez M, Goergen K, Gütler I, Halenka T, Karacostas T, Katragkou E, Keuler K, Kotlarski S, Mayer S, Meijgaard Ev, Nikulin G, Patarčić M, Scinocca J, Sobolowski S, Suklitsch M, Teichmann C, Warrach-Sagi K, Wulfmeyer V, Yiou P (2013) The simulation of european heat waves from an ensemble of regional climate models within the EURO-CORDEX project. Clim Dyn 41(9):2555-2575, DOI 10.1007/s00382-013-1714-z

Vrac M, Friederichs P (2015) Multivariateintervariable, spatial, and temporalbias correction. J Climate 28(1):218-237, DOI 10.1175/JCLI-D-14-00059.1

Walther A, Jeong JH, Nikulin G, Jones C, Chen D (2013) Evaluation of the warm season diurnal cycle of precipitation over Sweden simulated by the Rossby Centre regional climate model RCA3. Atmospheric Research 119:131-139, DOI 10.1016/j.atmosres.2011.10.012

Wilcke RAI, Mendlik T, Gobiet A (2013) Multi-variable error correction of regional climate models. Climatic Change 120(4):871-887, DOI 10.1007/ s10584-013-0845-x

Yoo C, Lee J, Yoon Y (2001) Climatological thresholds of daily rainfall. Journal of Hydrologic Engineering 6(5):443-449, DOI 10.1061/(ASCE) 1084-0699(2001)6:5(443) 

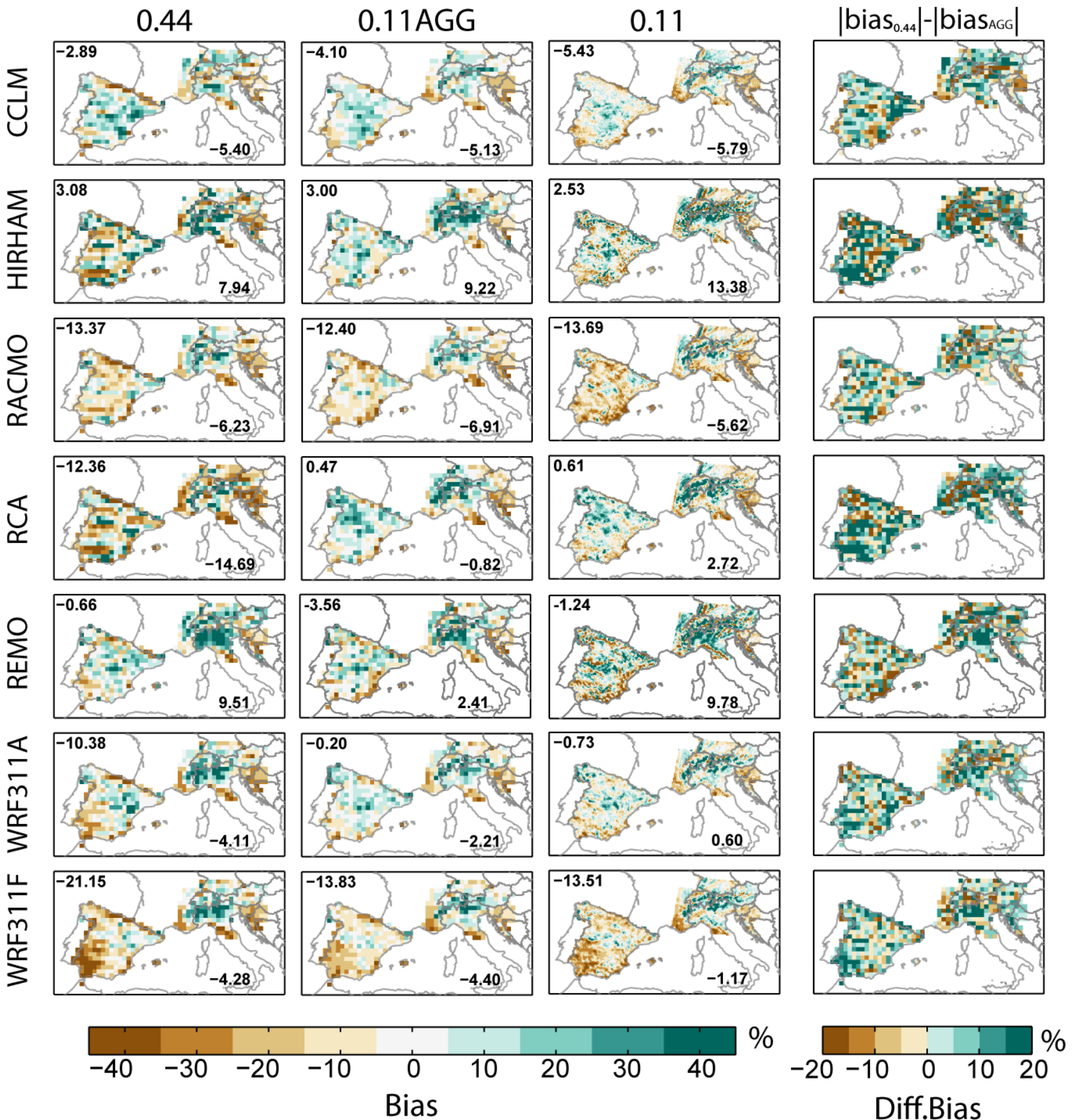

Fig. 2 Winter SDII relative biases (\%) for the RCMs (rows) at $0.44^{\circ}$ (first column), 0.11 AGG (second column) and $0.11^{\circ}$ (third column) resolutions. Values in the upper left and lower right corner represent the relative biases of the spatially averaged SDII in both regions. The fourth column shows the difference between the first two columns in absolute values. 

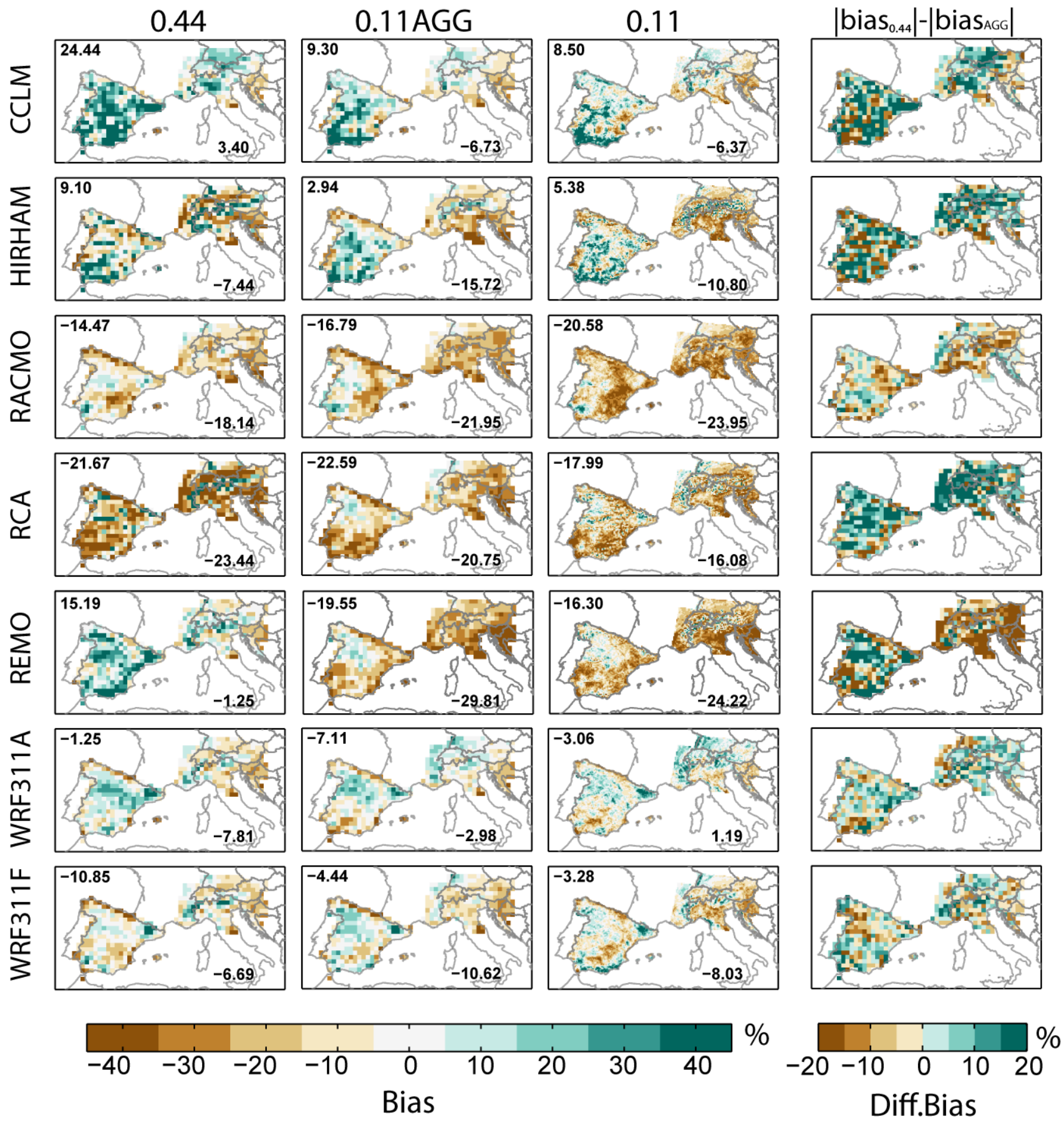

Fig. 3 As Figure 2, but in summer. 
Highest Wet Day Threshold $(\mathrm{mm}) \quad$ Wet Day Threshold $\approx 1 \mathrm{~mm}$

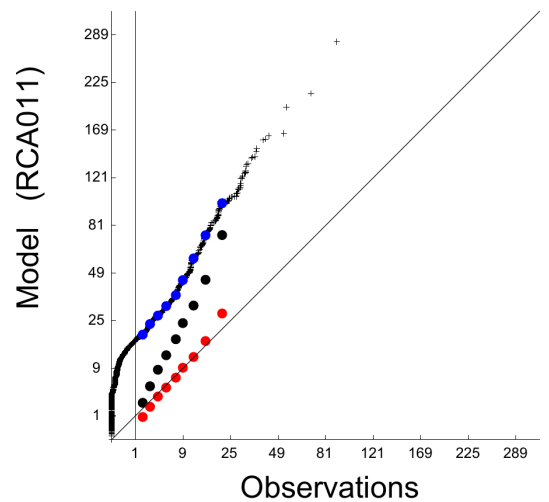

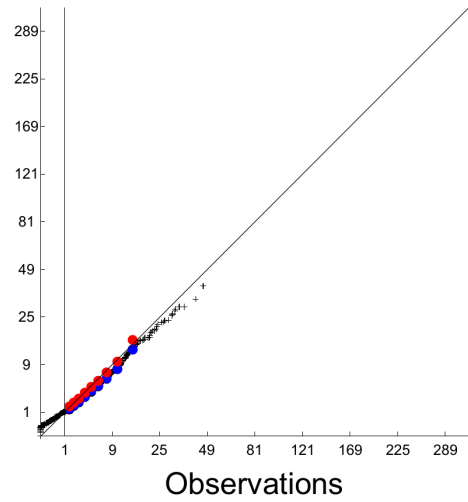

Wet Day Threshold $\approx 0.3 \mathrm{~mm}$

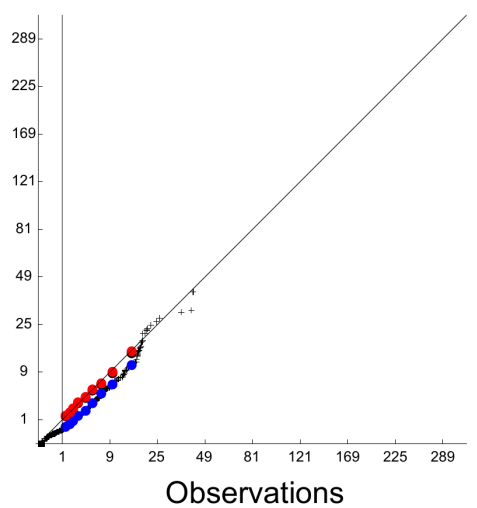

Fig. 4 q-q plots for 3 selected grid points from RCA011 simulations in winter (black crosses). These grid points corresponds to adjusted wet-day thresholds greatly exceeding $1 \mathrm{~mm}$ (left), around $1 \mathrm{~mm}$ (center) and under $1 \mathrm{~mm}(\approx 0.3 \mathrm{~mm}$, right). Values are presented in squared root scale with labels in the original units. The vertical line corresponds to $1 \mathrm{~mm}$ in the observations; its intersection with the q-q plot provides the adjusted threshold equivalent to $1 \mathrm{~mm}$ in the observations $\left(P^{*}\right)$. Dots show the deciles from the wet day distribution for $1 \mathrm{~mm}$ threshold (black), the adjusted wet day threshold (blue) and after local scaling (red). 90pWET corresponds to the last dot of each series. 

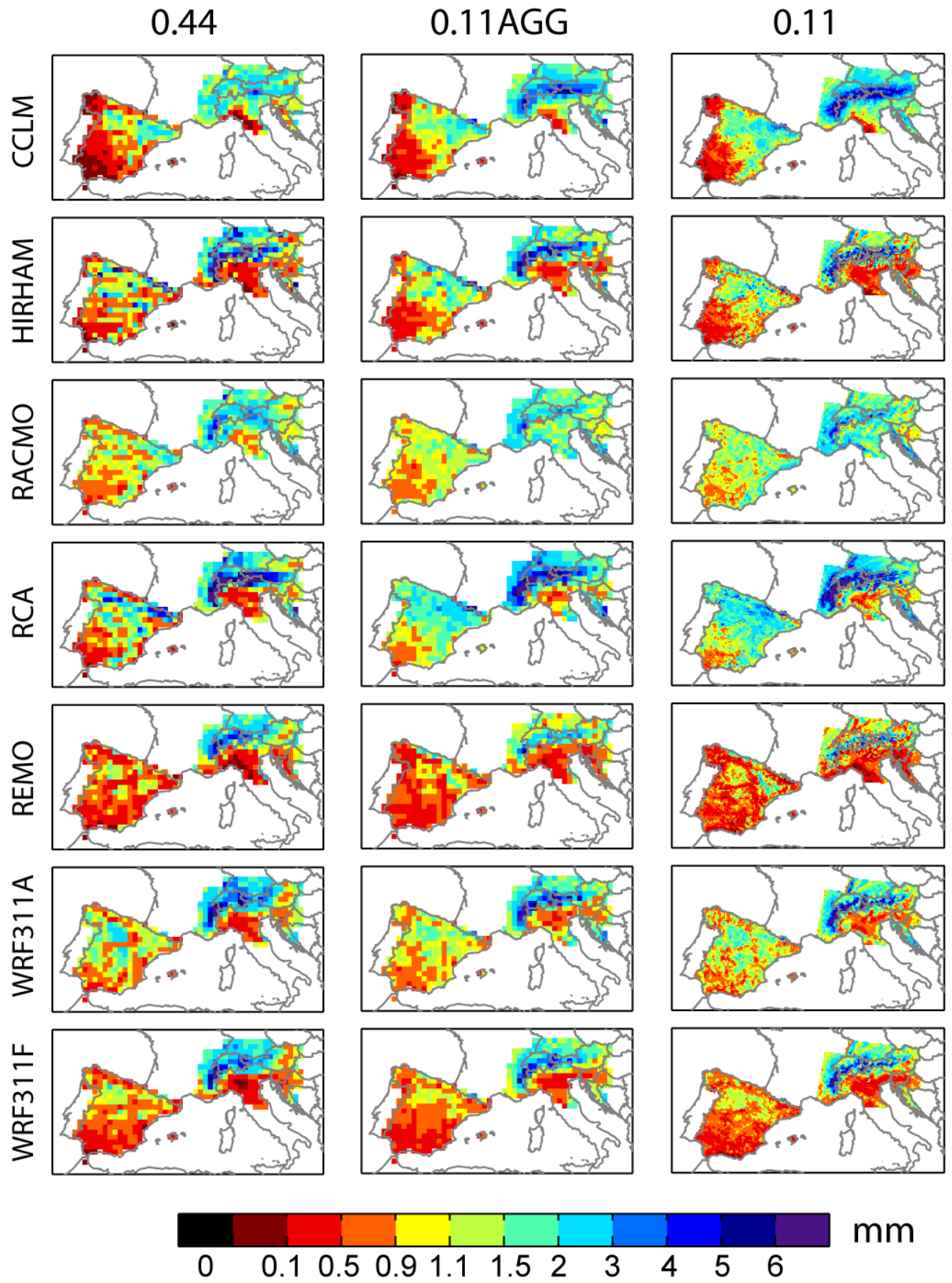

Fig. 5 Wet-day threshold equivalent to $1 \mathrm{~mm}$ in the observations for all the RCMs (rows) and resolutions (columns) in winter. For a better contrast of spatial differences, values are presented using a non-linear scale. Note that the black color represent $P^{*}=0$. 

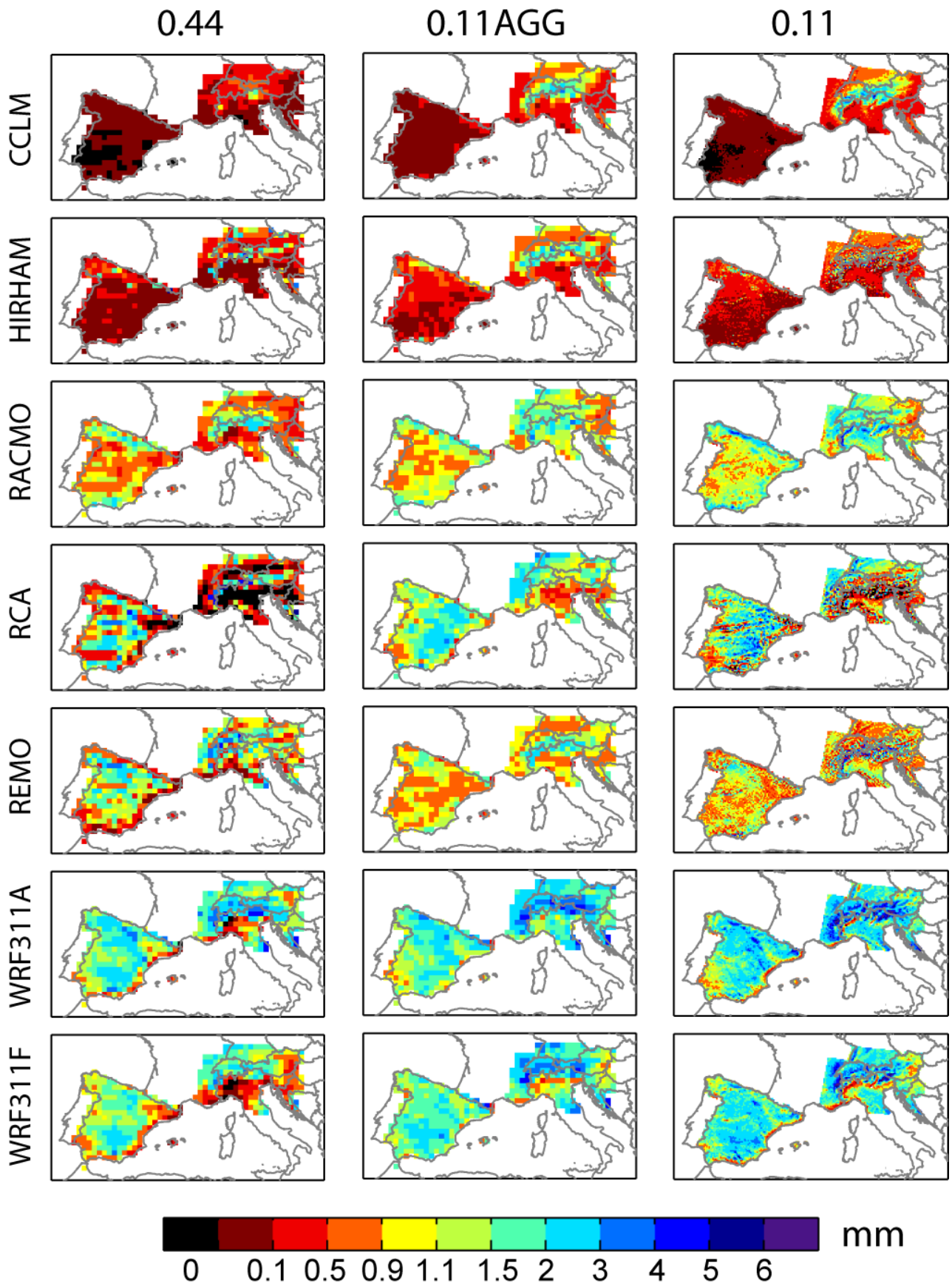

Fig. 6 As Figure 5, but in summer. 


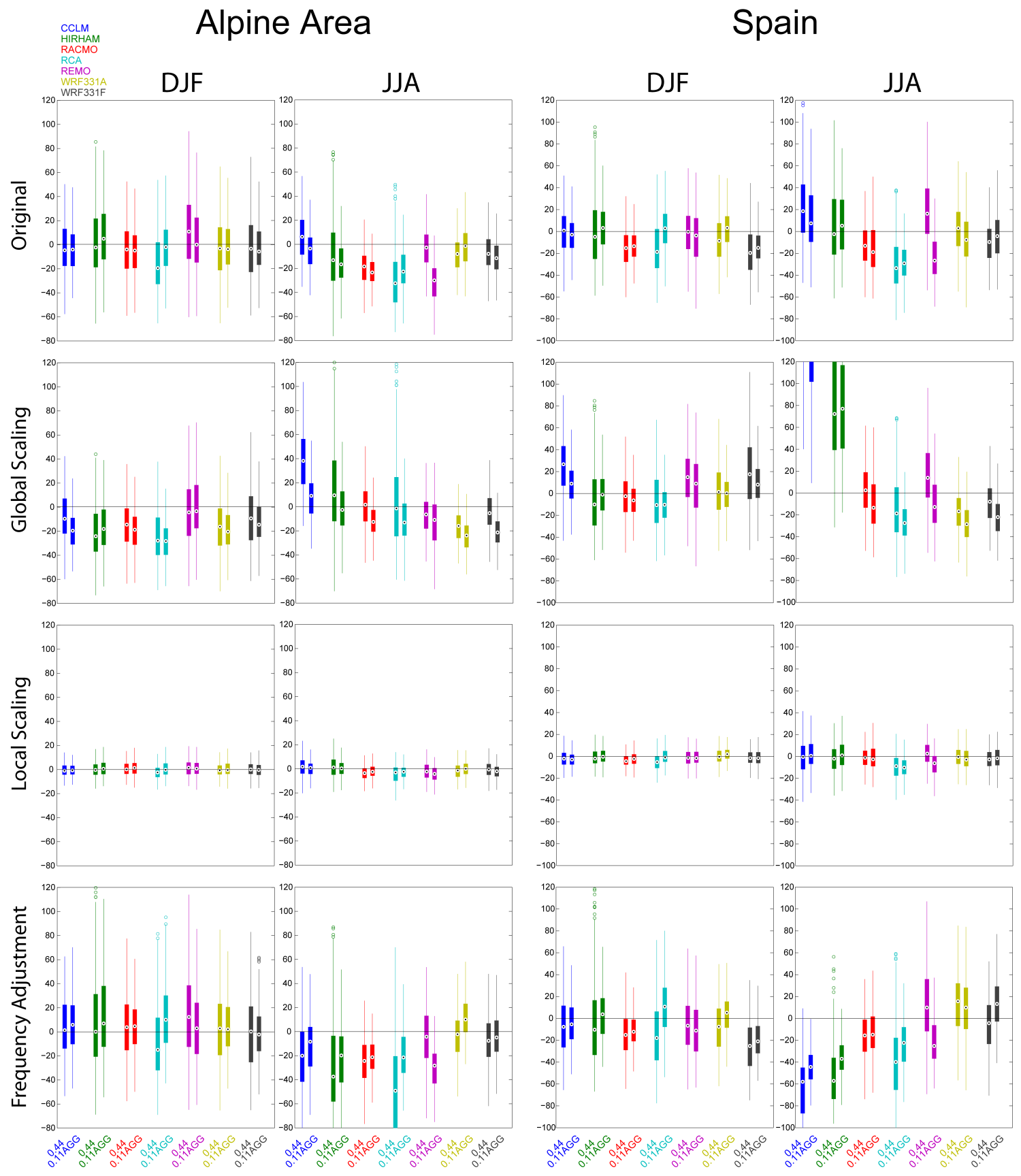

Fig. 7 Boxplots summarizing the spatial distribution of 90pWET relative biases (in \%) for winter (DJF) and summer (JJA) for both regions (columns). The 90th percentile is calculated with the standard $1 \mathrm{~mm}$ fixed threshold as reference (first row). Second to fourth rows correspond to the relative biases in 90pWET when GS, LS and FA corrections are applied, respectively. Each box corresponds to one RCM and resolution $\left(0.44^{\circ}\right.$ and $0.11 \mathrm{AGG}$ per RCM). The boxes show the interquartile range and the median (circle) but, for the sake of clarity, the whiskers extend only to the 5 th and 95 th percentiles. 


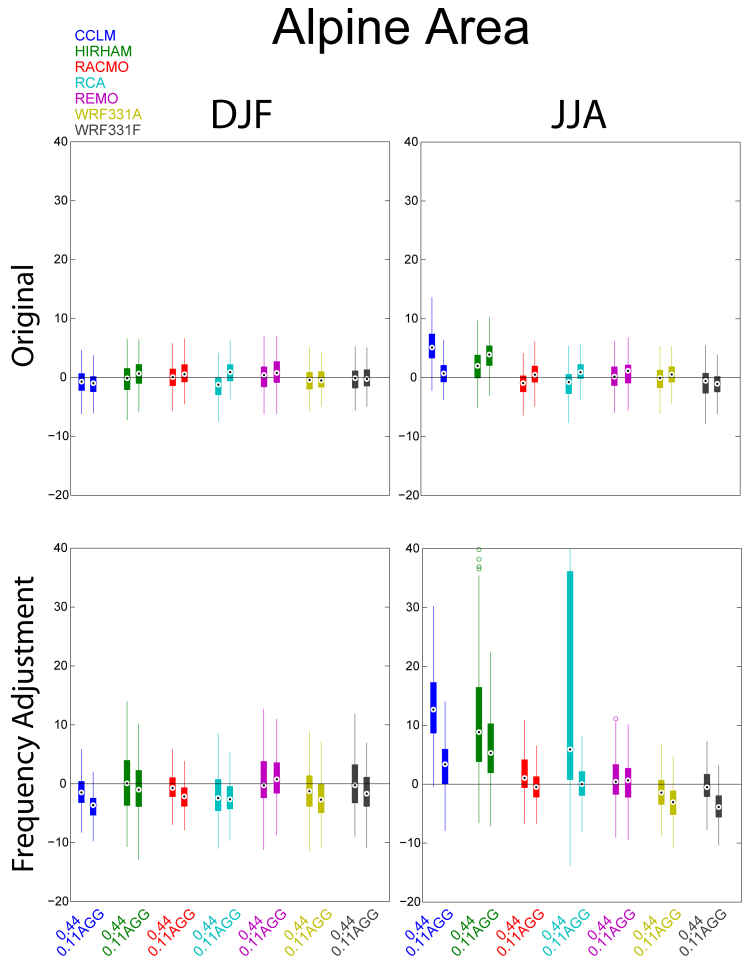

Spain
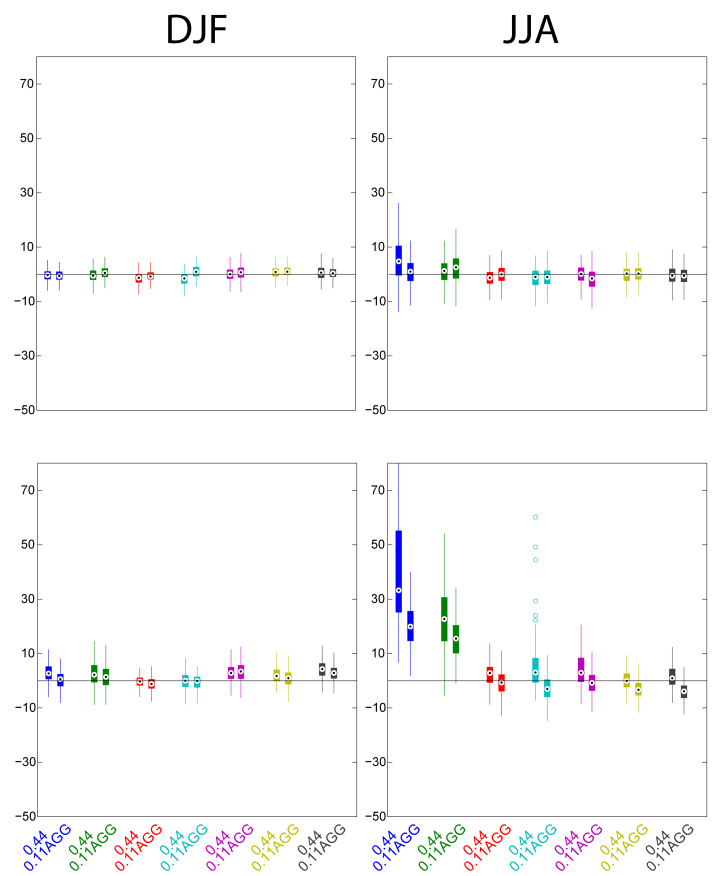

Fig. 8 As Figure 7, but for the absolute biases of R95pTOT (in \%). GS and LS corrections are omitted, since they do not affect this index. 


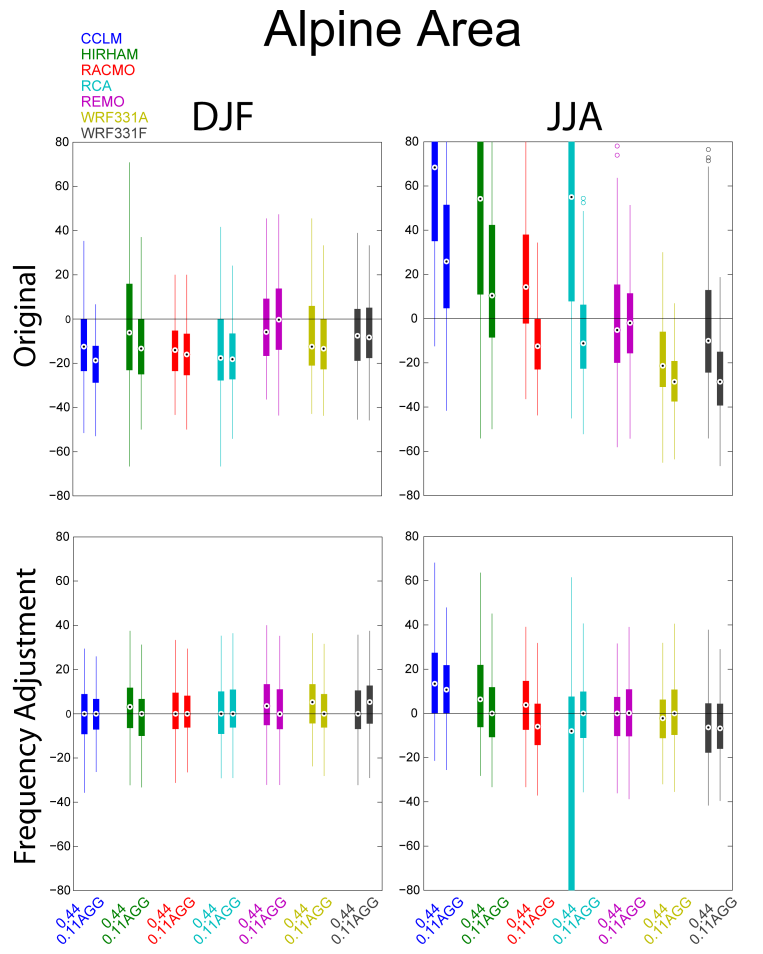

Spain
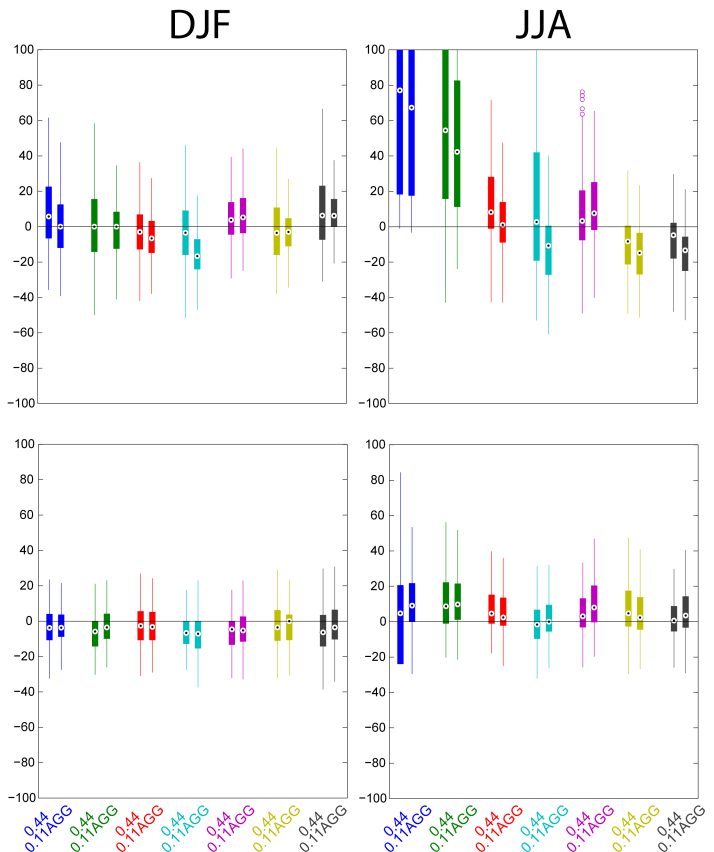

Fig. 9 Boxplots for the spatial distribution of CDD relative biases (in \%) for winter (left) and summer (right). The indicator is calculated with the $1 \mathrm{~mm}$ fixed threshold (first row) and with the adjusted wet-day threshold (second row). See Figure 7 for further details. 

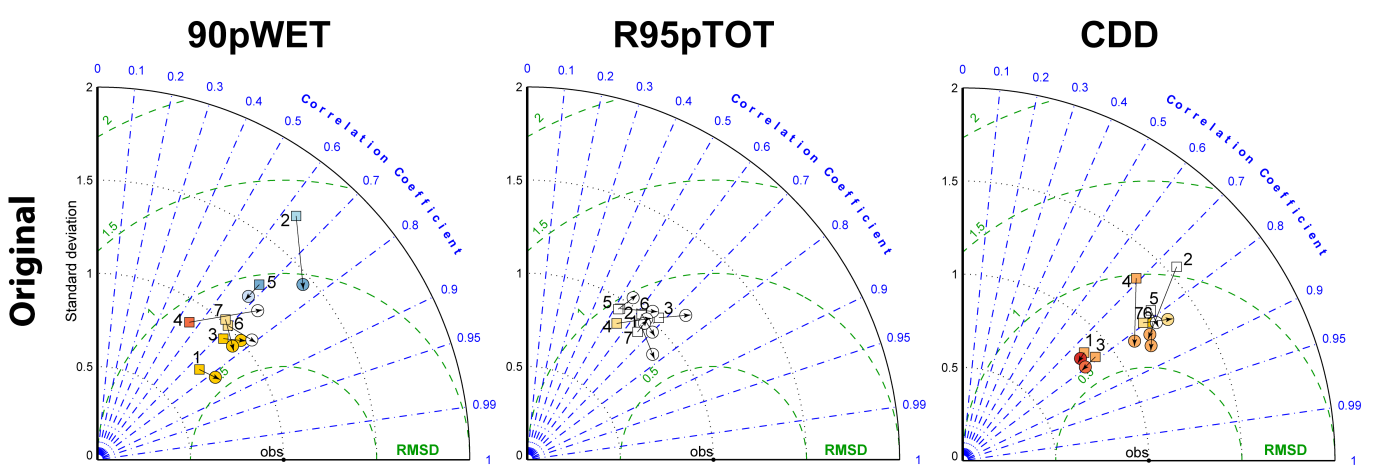

$\mathrm{N}^{\circ}$ 0.11AGG improving on $0.44^{\circ}$
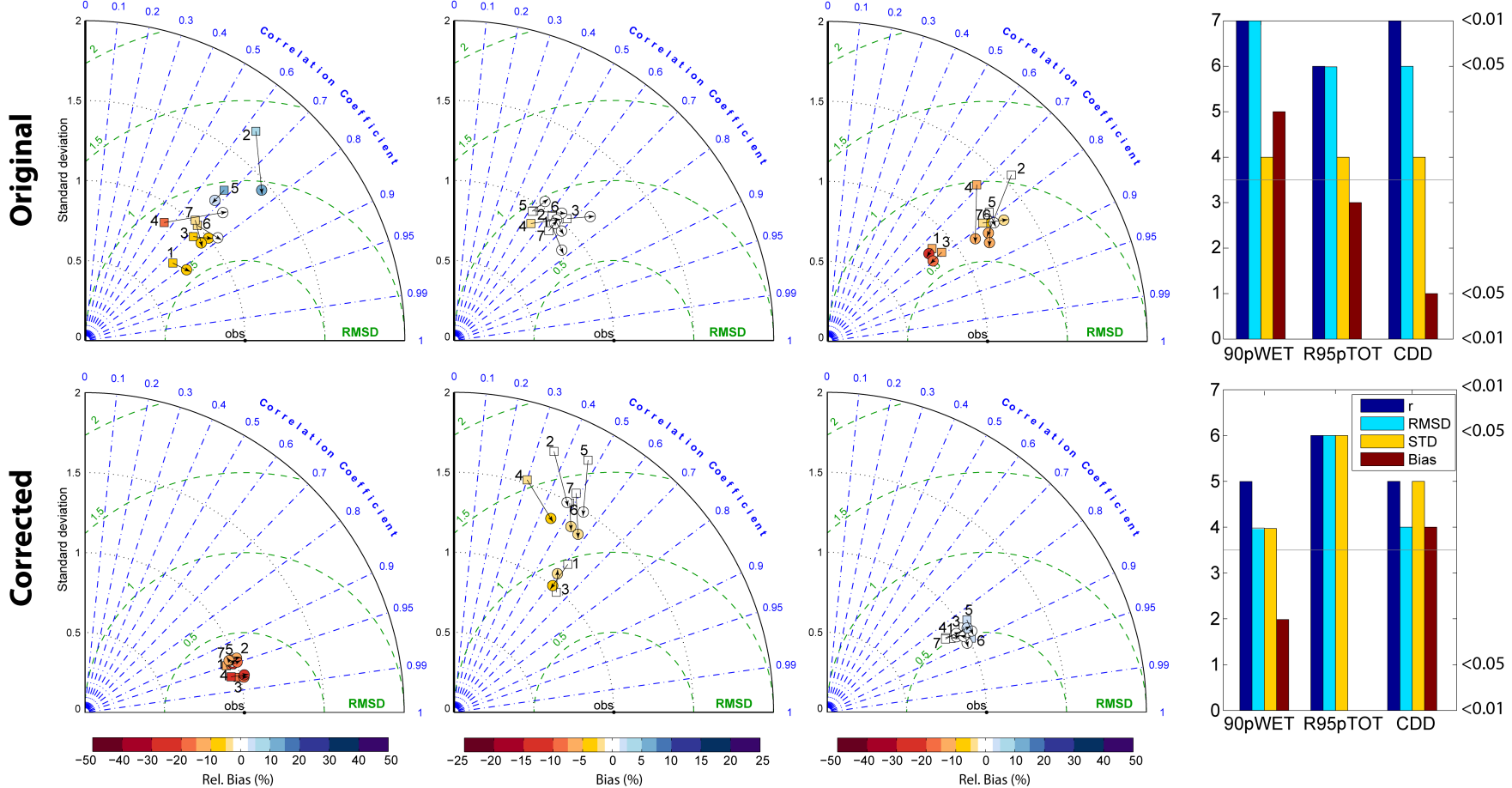

Fig. 10 Taylor diagrams for winter 90pWET, R95pTOT and CDD in the Alpine region. The first row shows the original data using a $1 \mathrm{~mm}$ fixed wet-day threshold. The second row shows corrected data (LS for 90pWET and FA for R95pTOT and CDD). Squares represent $0.44^{\circ}$ resolution and circles $0.11 \mathrm{AGG}$. Their colors correspond to the biases in the spatiallyaveraged index. The numbers close to the square markers identify the RCMs (see codes in Table 1). The right panel shows barplots of the number of RCMs at $0.11 \mathrm{AGG}$ resolution that perform better than the $0.44^{\circ}$ resolution in spatial Pearson correlation coefficient $(\mathrm{r})$, centered root mean squared difference (RMSD), variability (std) and bias. The results are statistically significant only when 6 or 7 RCMs improve upon the $0.44^{\circ}$ (see text). 